\title{
ELECTRON STIMULATED DESORPTION: $\underline{\text { A CRITICAL REVIEW }}$
}

Monte J. Drinkwine and David Lichtman

Department of Physics and the Laboratory for Surface studies

University of Wisconsin-Milwaukee

Milwaukee, Wisconsin 53201

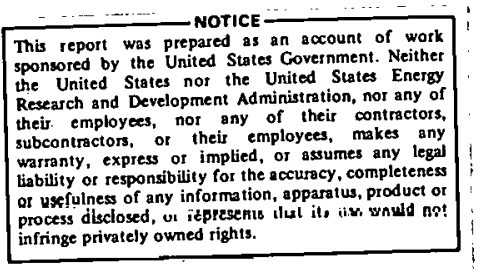

ABSTRACT

A critical review of the literature in the field of electron

stimulated desorption is presented. The material is covered through December 1975. The literature on electron-induced ion desorption using bombarding electrons with energy $<200 \mathrm{eV}$ has been reviewed in detail several times. This review, therefore, concentrates on electron-induced desorption of ground state and excited state neutrals and the effect of electron bombarding energy in the energy raige above several hundred ev. There is general agreement that ESD involves the direct interaction of the bombarding electron with the adsorbed species. Electronic transitions to anti-bonding modes result in the desorption of neutrals, excited state and ionic species. The cross sections are atomic in nature and vary from $10^{-16}$ $\mathrm{cm}^{2}$ to $<10^{-20} \mathrm{~cm}^{2}$. The interactions and cross sections are relatively independent of the substrate material. The largest cross sections occur for weakly bound molecular species. Although there is agreement on the qualitative character of the interaction, there is very poor agreement on the quantitative cross section values. Very little information exists at all on direct measurements of neutral desorption and the effect of. bombarding electron energy in the energy range above $500 \mathrm{eV}$. 


\section{DISCLAIMER}

This report was prepared as an account of work sponsored by an agency of the United States Government. Neither the United States Government nor any agency Thereof, nor any of their employees, makes any warranty, express or implied, or assumes any legal liability or responsibility for the accuracy, completeness, or usefulness of any information, apparatus, product, or process disclosed, or represents that its use would not infringe privately owned rights. Reference herein to any specific commercial product, process, or service by trade name, trademark, manufacturer, or otherwise does not necessarily constitute or imply its endorsement, recommendation, or favoring by the United States Government or any agency thereof. The views and opinions of authors expressed herein do not necessarily state or reflect those of the United States Government or any agency thereof. 


\section{DISCLAIMER}

Portions of this document may be illegible in electronic image products. Images are produced from the best available original document. 
The material on neutral desorption is divided into three parts, namely experiments involving total pressure measurements, partial pressure measurements, and detection of desorbing excited state neutrals. The following section considers high energy data. Finally, in the conclusion, recommendations regarding data required for the CTR program are discussed. 


\section{ELECTRON STIMULATED DESORPTION}

\section{A CRITICAL REVIEW}

\section{Introduction}

This review will consider material on electron stimulated desorption through December 1975. There has been a great deal of work done on ESD. Most of this work has been concerned with electron induced ion desorption using bombarding electrons of energy less than $200 \mathrm{eV}$. A number of reviews have dealt with this material in detail 17,33,39,40,50. Of major concern to the CTR program are data on neutral desorption and desorption caused by bombarding electrons of energy up to 10-20 KeV. This review will, therefore, concentrate on these two areas. The material naturally falis into two general categories. Section II will be conccrned with ESD of neutrals and section III will be concerned with the effect on ESD as the bombarding electron energy increases above $200 \mathrm{eV}$. Finally, in the conclusion (IV), we will summarize the status of knowledge in ESD as of today and suggest what research efforts are still required to provide the data needed by the CTR program. The nature of the material made it clear that a single chronological reference list and a single set of figures would be most appropriate.

During the literature search for this review, a most intriguing result developed. In all previous reviews and in hundreds of individual papers, credit for the first controlled experiments to study ESD on specific gas-loaded elemental metallic surfaces is 
given to G. Moore ${ }^{6}$ (1961): Credit for the initial ideas of the basic mechanism are given to Redhead ${ }^{13}$ (1964) and Menzel and Gomer $^{12}(1964)$. We have found several papers by Isikawal in a relatively obscure Japanese publication dating to 1942 in which not only controlled experiments on ESD are reported, but suggestions of models which are presently accepted as essentially correct, are clearly indicated. It is clear that Isikawa should be credited as the originator of controlled ESD studies. The reason for his lack of discovery is undoubtedly related to the appearance of these papers in Japan just at the beginning of World War II. The details of his observations will be presented in the appropriate sections in the review.

\section{ESD of Neutrals}

The area of ESD of neutrals will be divided into three separate subsections for historical as well as practical reasons. These three areas are: A) neutral desorption observed by measuring total pressure changes, B) neutral desorption observed by measuring partial pressure changes, C) ESD of metastable or excited neutrals. Because of the development of various vacuum and surface technologies these three areas follow a chronological sequence as well as covering the advancement of the understanding of ESD of neutrals in a systematic fashion. However, because of the nature of the problem and the methods of experimental study used, some of the areas are intermixed and intertwined in the 
literature. For this reason a complete separation has not been effected in the following discussion.

A. Neutral desorption observed by measuring total pressure changes

As commented on in the introduction, a remarkable piece of work was done on neutral ESD as early as 1942 by Isikawal'. He studied ESD of pure $\mathrm{H}_{2}$ adsorbed on a clean out-gassed polycrysta $1-$ Iine platinum surface (at room temperature and at liquid air temperature) by observing pressure changes in the system (using a Pirani gauge) during electron bombardment of the platinum sample. His results show variations depending on sample temperature, electron energy, electron current, and recent sample-system history. Of significance to this review is the data (Fig. 1) which shows that there is a threshold electron energy of about 8 to 10 eV needed before any desorption occurs. Also there are indications that for certain cases there exists a definite set of several maxima and minima (Fig. 2) in the desorption efficiency in the electron energy range below $60 \mathrm{eV}$. (This has also been found more recently by Redhead ${ }^{13}$ and zingerman and Ischuck ${ }^{23}$ for ionic ESD and by Madden 49 who investigated ESD indirectly using soft $x$-ray appearance potential spectroscopy.) No quantitative ESD yields were obtained in this early paper. However, based on these very early experiments, Isikawa proposed a mechanism (in detail) for ESD of neutrals, excited neutrals, and ions which is very similar to the mechanistic theory proposed later by Menzel and Gome ${ }^{12}$ (and independently by Redhead ${ }^{13}$ ) in 1964 - a time when ESD was beginning to be considered as an important area of study. It is interesting 
value is well into the region where "surface heating" effects can occur. Thus it is very likely that electron induced "surface heating" contributed significantly to their results.

We might note here in passing that electron bombardment (usually involving high current densities) had already been used for many years prior to 1960 for the outgassing and cleaning of metal parts in vacuum systems. This method was used for a variety of reasons - one of the most important being that electron bombardment was more thorough and effective than resistance heating alone (although actual temperatures of the degassed materials seldom exceeded or even reached temperatures normally attained when conventional heat-degassing methods were used). In terms of the discussion here it is important to realize that at least two effects are responsible for the effectiveness of cleaning out-gassing by electron bombardment: 1) ESD - all processes leading to desorption which proceed by an initial one step electron energy transfer, and 2) "surface heating" produced by the electron bombardment, which in many cases results in the entire sample reaching a high temperature due to the sustained input of large quantities of power. Due to the different mechanisms involved, one should expect total ESD yields to increase approximately linearly with increasing bombarding electron current, whereas total "surface heating" yields should vary in some way with the power density of the electron beam. Furthermore, from calculations ${ }^{46}$, it has been shown that even electron beams with power densities as low as $10 \mathrm{~mW} / \mathrm{cm}^{2}$ can cause significant surface heating leading to thermal desorption of adsorbed gases. 
Even when experiments concerned with ESD of neutrals have been carefully analyzed and the results reported with the above ideas in mind there are many cases when reports of true ESD are suspect because of the nature of the experiment and the experimental system itself. Except in cases where beam currents have been kept below $10^{-6} \mathrm{~A} / \mathrm{cm}^{2}$ using electron energies less than 1000 $\mathrm{EV}$ call une be truly certain that ESD is the real primary cause of neutral desorption. This problem of distinction between ESD desorption and surface heating desorption is not so serious when studying ESD of ions because heating seldom leads to ion production. On the other hand, both heating and ESD produce neutral desorption, often in similar quantities.

Using more refined methods Péterman ${ }^{11}$ (1963) pursued his earlier work ${ }^{7}$ in more detail. Using a pulsed electron beam with $270 \mathrm{eV}$ erieryy and current densities of 1 to $10 \mathrm{~mA} / \mathrm{cm}^{2}$ he bombarded pure nickel samples, observing ESD of neutrals by detecting pressure increases using a BAG (Bayard-Alpert gauge). In further ex-. periments using an Omegatron R.G.A., he found that $\mathrm{CO}$ and some $\mathrm{H}_{2}$ were the main constituents in the gas phase. after the nickel sample had been thoroughly cleaned by RF heațing, and that $C O$ was the only gas released during electron bombardment of the sample. An initial conclusion is that $c 0$ from the gas phase is adsorbed onto the clean sample and is consequently desorbed by electron bombardment.

By making some basic assumptions about pumping: speed, size of the system, etc., and using data obtained from BAG pressure measurements during ESD experiments approximate yield values were calculated. Two very different sets of results were found: 1) with a low co 
partial pressure of $\sim 1 \times 10^{-11}$ Torr and using a cleaned pure nickel sample an ESD yield of $8 \times 10^{-8}$ molecules/electron is calculated, 2) with a higher co partial pressure of $4 \times 10^{-10}$ Torr (which he claims is sufficiently high to allow co to adsorb onto the sample between beam pulses) the calculated yield value obtained is $2 \times 10^{-2}$ molecules/electron. It is also reported that for case 1) the number of desorbing molecules increases proportionately wi.th increasing beam power whereas in case 2) the number is independent of beam energy and increases proportionately with beam current.

The conclusion drawn here is that because of the low efficiency, case 1) must be a dissociation process whereas case 2) must go by a different mechanism. This conclusion is unlikely since, in case 1), the total number of desorbing molecules increases proportinnately with bcam power. (We must observe here that again average beam power densities of the order $>100 \mathrm{~mW} / \mathrm{cm}^{2}$ were used). It would be very hard to separate ESD and surface heating effects in this experiment. The most likely conclusion one might draw is that case 1)'s results are due primarily to surface heating effects while in case 2) there is some combination of surface heating and true ESD leading to the observed desorption efficiency. We might note here that simply because observed yield values are low ( $<10^{-6}$ molecules/electron) does not inherently mean that the observed process must be true ESD.

Another comment concerns the assumption that in pulsed beam' experiments sample heating problems are eliminated. Although no measurable heating may occur it must be noted here that surface 
heating may produce large surface temperature increases in very short times (less than a milisecond) which can produce observations similar to those expected for quantum processes. Also we must note that, as is well known today, ESD products come primarily from adsorbates which are weakly bound and therefore usually not present for sample temperatures greater than several hundred degrees Centigrade. The close proximity of hot filaments in many of the earlier experiments on ESD may have greatly affected the reported results due to possible warming of the target.

A great deal of interest arose in the early 1960's concerning anomalously high pressure measurements obtained using BAGs usually right after or during exposure to high partial pressures of active gases such as $\mathrm{O}_{2}, \mathrm{CO}, \mathrm{H}_{2}$ and $\mathrm{H}_{2} \mathrm{O}$. It was assumed that electron bombardment of the grid of the BAG and subsequent ESD of adsorbed $\mathrm{O}_{2}$, etc. was responsible for this anomaly. However, the exact nature of the desorbing species was in question. At first it was assumed that neutral desorption was the cause. Redhead ${ }^{8}$ (1962) indicated that most probably the anomaly was due to photons or excited neutrals. Further studies by Redhead ${ }^{9}$ (1963) and Hartman ${ }^{10}$ (1963) showed this not to be the case. The real cause of the anomalously high pressure readings was due to ion currents from ESD ions with energies of the order 5 to $6 \mathrm{eV}$. Redhead ${ }^{9}$ also stated that, although ESD ions were the real cause of the anomalously high collector current, for the case of $\mathrm{O}_{2}$ adsorbed on the grid, $\mathrm{O}^{+}$ESD ions were only a few percent of the total ESD product and that neutral oxygen comprised the rest. This was partially substantiated by Hartman ${ }^{10}$ using a mass spec- 
trometer during. electron bombardment of the grid. He noticed an increase in the 16 peak (0) but no corresponding incrëase in the 32 peak $\left(\mathrm{O}_{2}\right)$.

The very first very carefully controlled experiment producing ESD neutral yield values was conducted by Redhead ${ }^{13}$ (1964). Primarily interested in ion desorption he studied $\mathrm{O}_{2}$ adsorbed on molybdenum (at room temperature and higher) using apparatus previously described in $1963^{\circ}$. An important feature is that this is one of the few experiments of its time using a low enough beam power ( $1 \mu \mathrm{W} / \mathrm{cm}^{2}$ ) to insure that ESD was the primary mechanism producing: the observed results. Redhead assumes a first order type of mechanism for all ESD processes (this was described briefly earlier) which predicts an exponential decay of the ESD signal with time during bombardment with a constant beam current density. By measuring. the decay rate of his. ESD ion signal and assuming a value for the initial coverage of the molybdenum sample he finds cross section values for the total cross section $(Q)$ of the order $Q \simeq 1 \times 10^{-18} \mathrm{~cm}^{2}$. Moreover his calculations and measurements indicate that only about $2 \%$ of the total ESD product is released in ion form, the rest desorbing as neutrals. Again, as in $1963^{9}$, he claims that the neutrals are mostly atomic oxygen and uses Hartman's ${ }^{10}$ results for substantiation. Some important features of this work are: 1) the use of low enough power density to insure ESD as being the primary process investigated, 2) that $\mathrm{O}_{2}$ exists in two states on molybdenum (which are referred to as state 1) and state 2) and that the cross section for neutral ESD (and ion ESD) is approximately $10^{3}$ times greater for state 1) (which is weakly bound and disappears quickly as the sample 
is raised to $1000 \mathrm{~K}), 3)$ a discussion of the importance of ESD neutral desorption in measurements - reporting that approximately $98 \%$ of all ESD products are neutrals (this point cannot be over emphasized in terms of historical and fundamental importance), 4) the use of an indirect method to determine that the threshold energy needed for ESD of neutrals was the same as that for ESD of: 1ons (this result implies that the transition involved in ESD of neutrals is the same as that for ESD of ions except with a subsequent step involving Auger neutralization before desorption). These results and conclusions (comment number 4) are presently disputed and argued by Menzel ${ }^{25}$ as discussed later.

Other workers including Redhead ${ }^{20}$ have pursued studies similar to the above. Concentrating primarily on ESD of ions from active adsorbed gases on high refractory metals, ESD neutral data was obtained indirectly. Since there is little disagreement in basic yield results where low power electron bombardment has been used ( $\leqslant 1 \mathrm{~mW} / \mathrm{cm}^{2}$ ) there seems no need to cover this aspect any further. Also, the literature is discussed and reviewed in detail in this regard in the various reviews on $\operatorname{ESD}^{17,39,40,50}$. Redhead 33 (1970) also reviews ESD in general, concentrating on effects leading to erroneous total and partial pressure measurements. Again, he covers the literature pertinent to ESD in this area very thoroughly and completely.

In summarizing this subsection we would first like to point. out that ESD of neutrals had been universally accepted prior to 1942, (mostly by people working with vacuum tubes) before any controlled experiments had been done to detect it. There is a great. 
deal of reference to ESD of neutrals, yet even today very few direct measurements have been made. Secondly, much of the research that was done in this area is of little value in terms of obtaining true ESD yield data because surface heating effects were generally not fully considered and analyzed. Finally, it should be emphasized that most researchers in this area believed that the majority of the ESD products were neutrals, but it was not until 1964 that Redhead ${ }^{13}$ showed that the ratio of neutral to charged ESD species was approximately $10^{2}$. He also claimed that ESD cross sections are generally much lower than electron-gas phase interaction cross sections and that ESD neutral cross sections are in the range $10^{-18}$ to $10^{-21} \mathrm{~cm}^{2}$. This range of values is for the observed cross sections and includes the probability of the adsorbed species getting away from the surface after the initial electron interaction.

B. Neutral desorption observed by measuring partial pressure changes

The first controlled experiment attempting to detect ESD of neutrals by partial pressure measurements (Plumlee and Smith 4 (1950)) nad only negative results. They detected $\mathrm{O}^{+}$ions desorbing from their sample and assumed that the $\mathrm{O}^{+}$signal came from $\mathrm{O}_{2}$ adsorbed on the sample surface. They also looked for ESD of neutral atomic oxygen. Altiough their estimated efficiency for detection of ESD neutrals was only $10^{-2}$ smaller than that for ESD ions, they found no changes in the mass 16 signal which would correspond to desorbing neutral atomic oxygen. 
As mentioned in the previous subsection, Péterman ${ }^{11}$ (1963) studied ESD of neutrals. He measured total pressure'increases to obtain quantitative results giving yield values. However, he also used an Omegatron RGA to determine the nature of the desorbing species. He found increases in the co partial pressure indicating that this was the primary ESD neutral product in his experiment. Much of the early work done pertaining to surface studies was aided by the use of an Omegatron mass spectrometer (such as the one used by Péterman). It is sịnnificant to point out here that this type of RGA is not very sensitive to low partial pressures since it does not incorporate an electron multiplier. Another disadvantage this type of RGA has (for use in ESD work) is that desorbing neutral particles cannot be detected directly in a "single pass" manner since this device does not work on a "line of sight" principle. These two points concerning the use of an Omegatron are important when interpreting neutral ESD results because: 1) usually large bombarding electron current densities are needed in order to produce enough desorption to be detectable - enough so that thermal effects may become important, 2) it is not possible to determine if the neutral particles desorbed only from the surface undergoing bombardment because of the "line of sight" problem, 3) species (desorbing from the surface being bombarded) with high sticking probabilities may never even get into the omegatron.

Hartman ${ }^{10}$ (1963), in his previously mentioned paper, observed a partial pressure increase during his ESD experiments. He was the first to detect ESD of neutral atomic oxygen from a molybdenum grid which had recently been exposed to oxygen gas. He also noted that 
there was no corresponding increase in the $\mathrm{O}_{2}$ partial pressure, which indicated that adsorbed $\mathrm{O}_{2}$ desorbs by ESD on Iy as $\mathrm{O}^{+}$and neutral atomic oxygen.

Redhead ${ }^{14}$ (1964), continuing work similar to that mentioned previously ${ }^{13}$ in the first subsection, studied co adsorbed on molybdenum. He used a mass spectrometer to determine both the ESD ionic and neutral products. He found only $\mathrm{O}^{+}$ions and only $\mathrm{CO}$ neutrals. His conclusions were that (within the detection limits of his equipment) $C O$ desorbs by ESD only from the alpha state (weakly bound) and that the cross section for neutral co desorption was $10^{4}$ times greater than that for $\mathrm{O}^{+}$desorption $\left(10^{-16} \mathrm{~cm}^{2}\right.$ compared to $\left.10^{-20} \mathrm{~cm}^{2}\right)$. His previous experiments with $\mathrm{O}_{2}$ on molybdenum ${ }^{13}$ showed a similar cross section for neutral desorption $\left(\sim 10^{-16} \mathrm{~cm}^{2}\right)$ but the ionic cross section was larger $\left(\sim 10^{-18} \mathrm{~cm}^{2}\right)$. Again, the work was done with a low enough beam current density and electron energy so that one could be certain that ESD and not thermal desorption was the primary effect observed.

Kendall $15:(1964)$ studied gas evolution from electron multipliers in a system with a background pressure of $\sim 10^{-9}$ Torr. He found that, even after baking at $400^{\circ} \mathrm{C}$ overnight, significant "outgassing" occurred when the multiplier was operated with a $20 \mu \mathrm{A}$ collector current. $\mathrm{CO}$ and $\mathrm{H}_{2}$ were the major desorption products along with traces of $\mathrm{CH}_{4}$ and $\mathrm{CO}_{2}$. Crude approximate estimates indicate that at the beginning of the desorption, yields of the order $10^{-2}$ to $10^{-3}$ molecules/electron are obtained - in agreement with Redhead's ${ }^{13}$ and Péterman's ${ }^{11}$ results for desorption near the start of electron bombardment. Electron bombardment of the collector 
and the last dynode of the electron multiplier and consequent ESD was considered to be the primary cause of the gas evolution. Kendall asserts that true ESD rather than electron bombardment heating is responsible for the observations because of the very short time lag between bombardment and desorption. However, in view. of the power transferred to the collector and last dynode $\left(\approx 100 \mathrm{~mW} / \mathrm{cm}^{2}\right.$ ) we feel that surface heating (which can produce desorption products almost instantly) cannot be completely eliminated as a possible cause. Kendall observed that the partial pressures increased roughly linearly with the collector current. Since no observations of pressure changes with electron energy were reported this result alone cannot provide conclusive evidence of ESD.

In an attempt to determine the main cause of gas desorption in electron storage rings Fischer and Mack ${ }^{16}$ (1965) focused their attention on electron induced desorption considering electron energies in a range expected for electrons produced by the photoelectron effect due to synchrotron radiation. Although they conducted a careful and thorough study using OFHC copper and 304 stainless steel targets, we feel that the observed results may not have been primarily due to true ESD. Beam powers used were well into the range where significant surface heating:occurs and even though the sample was externally water cooled this procedure does not eliminate the possibility of producing relatively high surface temperatures where the electron beam dumps its energy. (Some critical comments on this and other works will be presented later. in this subsection.) In this study, the samples were chemically cleaned before introduction into the vacuum system and subsequently. 
baked in vacuo to $250^{\circ} \mathrm{C}$ for 24 hours. They found $\mathrm{CO}, \mathrm{H}_{2}, \mathrm{CO}_{2}$ and o to be the main desorption products due to electron bombardment. Base pressures before electron bombarament were generally $10^{-10}$ to $10^{-9}$ Torr. Yield values for $\mathrm{CO}$ and $\mathrm{H}_{2}$ were obtained (for the copper and stainless steel samples) which ranged in both cases from $10^{-3}$ molecules/electron initially to $\sim 10^{-6}$ molecules/electron after several hours (sometimes days) of continuous electron bombardment. Although the true mechanism responsible for these observations may be in doubt, it is useful to note that bombardment of contaminated surfaces (even those which have been baked thoroughly) with moderately low power electron beams can initially desorb reasonably large amounts of neutral $\mathrm{CO}, \mathrm{H}_{2}$, etc. ( $10^{-2}$ to $10^{-3}$ molecules/. electron). Furthermore, the target can be "cleaned up" by continuuous bombardment, but in most cases it takes several hours before the yleld values tàl signitlcantly (n $10^{-6}$ molccules/clectron). This is an important result pertaining to high energy machines including CTRs.

We have stated many times in this paper that a considerable amount of work has been done purporting to be solely concerned with true $\operatorname{ESD}^{7}, 11,15,16$, etc. We believe much of this work is in fact hopelessly complicated by the added feature of possible surface heating. One objection to this criticism is that (especially for unbaked targets) if surface heating is of importance, $\mathrm{H}_{2} \mathrm{O}$ desorption should be expected as is the case when targets are resistively heated. It is found that the desorption products from electron bombardment contain at most a few percent of $\mathrm{H}_{2} \mathrm{O}$. McCracken and coworkers $^{19}$ (1967) commented on this very point when they studied ESD 
of gas from stainless steel surfaces.

MCCracken, et. al. ${ }^{19}$ bombarded stainless steel with $600 \mathrm{eV}$ electrons using.current densities ranging from .1 to $200 \mu \mathrm{A} / \mathrm{cm}^{2}$. They found yield values ranging from $\sim 5$ molecules/electron initially, later dropping to $\sim 10^{-6}$ molecules/electron after a considerahle time of continuous bombardment. The initial high yields were transient, decaying to values of about $10^{-3}$ molecules/ electron in a matter of minutes. They also calculated cross section values which were found to range from $10^{-16} \mathrm{~cm}^{2}$ initially falling off to $\sim 10^{-20} \mathrm{~cm}^{2}$ after long periods of continuous bombardment.

An important feature of their reported results is that a large variation in initial yield values was obtained depending on the pretreatment of the target. On the other hand, initial desorption cross section values varied very little from sample to sample. Samples that were chemically cleaned, placed into the vacuum chamber, and then bombarded had initial yields of the order 5 molecules/electron. Samples which had been thoroughly baked before bombardment had initial yield values of the order $5 \times 10^{-4}$ molecules/electron. However, initial desorption cross sections were very similar for all samples regaraless of pretreatment - approximately $10^{-16} \mathrm{~cm}^{2}$.

We should point out here that there is a considerable difference between the nature of desorption yield values and cross section values. Yield values depend on the sample coverage as well as the strength of the interaction involved. The cross section value is a measure of the strength of the interaction 
regardless of the coverage. For instance, if the state responsible for ESD products has a high coverage and a high cross section value the measured yield value can be high. If on the other hand this. same state has a coverage say $10^{-4}$ times smaller than before, the measured yield value will be $10^{-4}$ less. This argument is true for either a true ESD process or for a surface heating process. The cross section for a given surface state stays essentially the same regardless of its coverage.

In measuring yield values one needs to know the number of bombarding electrons and the number of ESD products (ions; neutrals, etc.). The first is easy. The second requires knowledge of pumping speed, system volume, detection efficiency, etc. - all these things can be estimated reasonably well. In determining absolute desorption cross section values one needs to know all the above as well as the coverage of the particular state of the adsorbate producing the desorption products. This last is very difficult to know exactly and can only be estimated with any accuracy for a few. weli defined systems (i.e. single crystal surfaces with only one gas adsorbate). Another way to determine the cross section is to plot logarithmically the decay of the desorption signal with time. Assuming that the mechanism is first-order a straight line should result and the desorption cross section is obtained from the slope of the line; This method is more accurate since coverage estimates are not necessary.

In any case, it is easily seen that desorption cross section values are of prime importance. Yield values alone give little useful information concerning ESD. For this reason we will hence- 
forth concentrate on reporting cross section values wherever possibie.

Considering the work done by McCracken, et. al., again, we can see that although initial yield values varied considerably, the important feature - the initial neutral desorption cross section - was about the same for all samples tested (i $10^{-16} \mathrm{~cm}^{2}$ ). After a considerable amount of electron bombardment the final cross section dropped to a value of $\sim 10^{-20} \mathrm{~cm}^{2}$ for most samples. This is in agreement with most other work cited so far, and even though McCracken posed the question concerning little or no detected $\mathrm{H}_{2} \mathrm{O}$ desorption it is still difficult to imagine these resulț being due to true ESD alone. Again, the bombarding power used in these experiments was well into the range where surface heating can occur. Also, considering initial yields of as high as five or tën molecules/electron one cannot reconcile this with the accepted mechanism that ESD is a quantum process. Although secondary electrons produced by the primary beam may contribute to the ESD yield it is unlikely that these secondary electrons can possibly account for yields this large. Another comment is that although $\mathrm{H}_{2} \mathrm{O}$ desorption is found to be at most a few percent of the total desorption product, we have found no quantitative determinations of the composition of the neutral desorption products at the beginning of electron bombardment when desorption efficiencies are reported as being very large. In the previously mentioned work by Fischer and Mack ${ }^{16}$ they found the initial desorption. spectra to have mass peaks at m/e ratios of 16 , 17, and 18 which quickly disappeared leaving primarily $\mathrm{CO}$ and $\mathrm{H}_{2} \cdot$ (Quanti- 
tative results were not reported:) In view of this it is reasonable to assume that initially desorption is a combination of ESD and surface heating with ESD becoming the more predominant effect with continuous bombardment:

Dawson ${ }^{21}$ (1967) investigated outgassing of various glass targets during electron bombardment. An arrangement was made using the secondary electron emission properties of the glasses to control the surface potential, thus preventing unwanted charging effects. A magnetic sector RGA was used in order to detect direct line of sight desorption products. Molecular oxygen was found to be the predominant desorbing species from the various glass targets. Dawson also found that for electron energies below $500 \mathrm{eV}$ the yield was proportional to the power indicating thermal processes. For electron energies of 500 to $1000 \mathrm{eV}$ the yield was proportional only to the current. This result had been found previously for metal targets as well. 16 This indicates that another mechanism besides surface heating may be responsible for desorption in this energycurrent range. Yield values of $\sim^{-6}$ molecules/electron are reported; but no cross section evaluations were attempted. The important feature to note here is that molecular rather than atomic oxygen is observed to desorb from a glass target during electron bombardmen't.

Garwin, et. al. ${ }^{26}$ (1968) made a particularly careful study. of the electron induced desorption of co from aluminum. Most reported results were obtained using power densities low enough to insure ESD as being the primary mechanism for the observations. A theoretical model was developed which fit their experimental 
data quite well while taking into account a multitude of possible effects such as readsorption, surface to bulk diffusion, different coexisting surface states, thermal desorption, etc. A quadrupole mass spectrometer (which was not in line of sight of the target surface) was used to monitor the changes in the partial pressures during electron bombardment. As found by others, partial pressures of $\mathrm{H}_{2}$ and $\mathrm{CO}$ (and in smaller amounts $\mathrm{CH}_{4}$ and $\mathrm{CO}_{2}$ ) were found to increase during electron bombardment. The co partial pressure was monitored for these experiments. Total background pressures were typically $\sim 10^{-10}$ Torr.

They observed ESD of neutral CO from several states simultaneously. This is shown clearly in Fig. 3 where one sees the transient response following repopulation at reduced temperature. Their explanation for this effect is that since high cross section states are desorbed more easily than the low cross section states one should see a rapid decay in the ESD neutral co signal (after readsorption is allowed to take place) followed by a slow decay in the signal corresponding to desorption from low cross section states. Another effect clearly demonstrated is that equilibrium populations of various surface states may be increased by either decreasing the bombarding current or increasing the base pressure. In the latter case the higher cross section states will depopulate whereas the lower cross section state can approach saturation values. This is clearly shown in Fig. 4 where the $c 0$ desorption rate reaches a constant value at the higher pressure and continues to decay at the lower pressure. They also found that the presence of $\mathrm{H}_{2}$ in the gas phase has a marked effect on the co desorption. The co adsorption 
is increased during repopulation and the cross section for ESD of CO is affected as well. They found the cross section for ESD of neutral co from aluminum to have a maximum for bombarding electrons in the energy range 200-400 ev. For electrons with an energy 100 $\mathrm{eV}$ it was found that the cross sections varied from $\sim 10^{-17} \mathrm{~cm}^{2}$ to $\sim 10^{-20} \mathrm{~cm}^{2}$ depending on conditions and the past history of the target.

Menze1 ${ }^{25}$ (1968) studied ESD of neutral Co from tungsten in an attempt to learn more about the ESD mechanism. One question of importance is whether or not ESD of neutrals always follows the same mechanism as that for ESD of ions. That is, does neutral de-: sorption always proceed (first) by transition to a surface ionic state with consequent neutralization and desorption via Auger neutralization while the ion is receding from the surface?. Is this the on $\perp y$ possibility, or can ESD of neutrals occur directly via a transition to an anti-bonding state of the adsorbed particle? Menzel studied these various possibilities by observing thresholds at which ESD of neutrals occur. In the first case (Auger neutralization) the threshold energy should be the same for ions and neutrals, while in the second case (transition directly to an antibonding neutral desorption state) the threshold energy for neutral desorption should be considerably lower than that for ionic desorption.

Menzel used a magnetic sector mass spectrometer to detect the ESD ion and neutral signals. In order to maximize the collection efficiency for neutrals the target was placed in close proximity and in line of sight of the spectrometer ionization chamber. 
UHV techniques were used along with careful dosing of the clean sample in order to minimize complications of analysis. Results were obtained with the target at various controlled temperatures using electron beams with various energies and current densities. Attempts were made to reduce any significant surface heating caused by the electron beam, but Menzel did comment that in some of the observations such thermal effects may have caused minor amounts of desorption.

This paper concentrated in detail on trying to determine the populations of various surface states of Co (virgin, alpha, and beta) as a function of temperature using mainly ESD ion desorption data with the added assistance of ESD neutral desorption data. The results of significant importance to us are: (1) Desorption cross sections for neutral $\mathrm{CO}$ on tungsten using $100 \mathrm{eV}$ electrons were found to be approximately $10^{-18} \mathrm{~cm}^{2}$ to $10^{=17} \mathrm{~cm}^{2}$ for $\mathrm{CO}$ in the alpha state. Beta state cross section values were so small as to be undetermined by this experiment ( $10^{-20} \mathrm{~cm}^{2}$ ). The ratio of ESD neutrals to EST ions is approximately $10^{2}$. (2) Thireshold measurements for neutral desorption show a value of $i \cdot 5 \mathrm{eV}$ (as indicated in Fig. 5), about $10 \mathrm{eV}$ less than that needed for ion desorption. This indicated that the transition involved in ESD of neutrals. (in some cases) is different than that for ESD of ions. At least some ESD neutrals must be produced by excitation directly to an anti-bonding state in order to obtain a threshold value as Low as $5 \mathrm{eV}$. (Menzel's observations also indicated that the desorption mechanism for neutral production may be different than that for ESD of ions at higher energies as well.) 
Menzel's results concerning the low threshold energy needed for ESD of neutrals ( $2 \mathrm{eV}$ ) provoked considerable interest and controversy by other workers in the field. However, little was done to independently check his findings. In a review paper Menzel ${ }^{32}$ (1970) discussed his previously obtained results pertaining to neutral desorption ${ }^{25}$, concentrating in some detail on the possible mechanism for neutral ESD. Again he indicated that, considering the low threshold needed for neutral ESD, many neutrals are probably desorbed by a direct transition to an antibonding state. No new experiments were cited to help substantiate his position. Then, later in 1970 , Nishijima and Propst ${ }^{37}$ published a paper which did in fact give further verification of Menzel's earlier work ${ }^{25}$ concerning the low threshold needed for ESD of neutrals.

Nishijima and propst ${ }^{37}$ caretuily ștudied adsorption of $U_{2}$ ' $\mathrm{CO}, \mathrm{CO}_{2}, \mathrm{H}_{2}, \mathrm{~N}_{2}$, and $\mathrm{H}_{2} \mathrm{O}$ on tungsten using a specially designed apparatus for the study of ESD. The analyzer used was capable of accurately measuring energy distributions of desorbing ions, threshold energies, and $\mathrm{m} / \mathrm{e}$ ratios of the desorbing ions. Their experimental procedure involved careful cleaning of the sample under UHV conditions, controlled dosing of the cleaned sample with pure gases at $\sim 300 \mathrm{~K}$, and bombardment of the sample with carefully monitored electron beam current density and energy with subsequent energy and mass analysis of the desorbing ions. of interest here are their results comparing total desorption cross sections with ionic desorption cross sections as a function of energy. With $\mathrm{O}_{2}$ adsorbed on tungsten they found little difference 
in the relative shapes of the cross section vs energy curves in the energy range $>40 \mathrm{ev}$, but for the energy range $<40 \mathrm{eV}$ there was a marked difference. Not only is the general shape somewhat different for the lower energy range but there is a definite indication that the threshold for the total cross section curve (which is due mostly to ESD of neutrals) is at least some few ev less than the threshold for the ionic cross section curve (Fig. 6).. This is a definite independent verification of Menzel's mechanistic theory which proposes that neutrals can desorb by electron excitation to an anti-bonding state. Nishijima and Propst's results concerning neutral desorption cross sections compared to ionic desorption cross sections are, however, in disagreement with Menzel for higher primary electron energies. Comparing total cross sections with ionic cross sections Nishijima and Propsl round little diference in the cross section vs energy curves for the higher energy range. This result indicated that the primary mechanism producing ESD of ions and neutrals is the same for energies $>40 \mathrm{eV}$. This is of particular interest, not only because this does not agree with Menzel's ${ }^{25}$ results but also because their cross section vs energy curves for ion desorption using electron energies $>100 \mathrm{eV}$ do not agree with work done by many others investigating ESD (this will be discussed in more detail in the later section on high energy ESD). Madey and co-workers ${ }^{38}$ (1970) decided that there might be a possibility of checking the validity of the theories concerning the mechanism of ESD proposed by Redhead ${ }^{13}$ and Menzel and Gomer ${ }^{12}$ : Independently proposed and basically the same, the two theories 
differed the most when considering ESD of neutrals. Redhead assumed that all ESD species (ions, neutrals, excited neutrals) were first excited through a Frank-Condon transition to an ionic nonbonding state. Menzel and Gomer also allowed for a direct excitation to an anti-bonding state for the production of neutral ESD species. This last point had been brought out in more detail by Menze $1^{25,32}$ as discussed above. Both theories suggested that for ESD of ions the absolute cross sections should depend on the mass of the desorbing ionic particle to the $\frac{1}{2}$ power. If ESD of neutrals occurs by an ionic intermediary (with subsequent Auger neutralization) the absolute cross section for ESD of neutrals should also depend on $\mathrm{m}^{\frac{1}{2}}$ for each desorbing neutral species. If, however, ESD of neutrals occurs by direct excitation to a neutral antibonding state the cross section should be mass independent. Madey, ct: al. 38 devided lu determbne $1 \mathrm{f}$ these theories were indeed valid by investigating the above mentioned mass effect. This was done by conducting ESD experiments on $\mathrm{O}_{2}$ adsorbed on tungsten using different isotopes of oxygen $\left({ }^{16} \mathrm{O}_{2}\right.$ and $\left.{ }^{18} \mathrm{O}_{2}\right)$ under the same conditions. Cross section measurements were made and compared for each case.

In the above work Madey, et. al. ${ }^{38}$ found an ionic cross section ratio of $\mathrm{Q}_{\mathrm{O}_{16}}^{+} / \mathrm{Q}_{\mathrm{O}_{18}}^{+}=1.55 \pm .15$ which agreed quite well with the value of 1.61 predicted by Redhead's and Menzel and Gomer's theory. Total cross section ratios of $\mathrm{Q}_{\mathrm{O}_{16}} / \mathrm{Q}_{\mathrm{O}_{18}}=$ $1.06 \pm .06$ were found. (As mentioned earlier, total.cross section values are usually assumed similar or the same as neutral cross section values because ESD neutrals outnumber ionic species 
by more than ten to one.) Depending on the assumptions one makes, the theoretical predicted cross section ratio value for the total cross section varied, but in every case all calculations predicted a greater value than the one measured. These results lead to the following conclusions: (1) the production of ions by ESD follows the theoretical mechanistic model proposed, (2) the primary method for the produrtion of neutrals by ESD docc not involve the same transitions as that for the production of ions.

Since the proposed mechanism for neutral production involving direct excitation to anti-bonding states would be mass independent and the above results were mass independent (within experimental error) one might conclude that direct excitation to anti-bonding states is the primary mechanism for ESD of neutrals. Although the above results appear to substantiate this alternate mechanism proposed by Menzel and Gomer for ESD of neutrals it is not as conclusive as verification using accurate threshold measurements. Madey, et. al. point out that the assumption that the decrease in. ion current (which is how the total cross section was measured) as a function of bombardment time is due only to the desorption of neutrals and ions may be erroneous. It may be that surface conversion processes from active to inactive ESD states may be occurring and that they may dominate the decay of ion current with bombardment time. If this were true the above conclusions concerning ESD of neutrals based on the results of Madey, et. al.'s work may be incorrect.

We would like to remark here that, as stated by Madey, et. al. , results obtained by an indirect approach may be complicated 
by a variety of possible causes other than the process of interest, and are consequently subject to criticism. Although researchers may know that neutrals are desorbing in their experiments (either by observing pressure increases or detecting the species directly with a mass spectrometer) unless direct measurements are made rather than indirect measurements (determination of total cross section based solely on ion current measurements) results and consequent interpretations cannot be considered conclusive. In regard to the controversy about neutral desorption via a direct excitation process, Menzel's direct measurements of the low threshold energy needed for neutral desorption are the only reliable results of a recent nature available at this time. Perhaps of secondary interest here is the fact that substantiating evidence of a direct nature has existed since 1942. Isikawa ${ }^{1}$ in his plevieusly luenliuned study of $\mathrm{H}_{2}$ adsorbed on platinum observed a threshold energy for neutral desorption below $10 \mathrm{eV}$. Although his techniques may not have been as sophisticated as those in current use, his results can be considered valid in this respect. It is unfortunate that this evidence has been so overlooked until now.

Klopfer $29,30(1970)$, using techniques and apparatus similar. to those of Menzel 25 , investigated ESD of both ions and neutrals in an attempt to gain a more detailed knowledge of the bonding states of $\mathrm{H}_{2}, \mathrm{O}_{2}$ and $\mathrm{H}_{2} \mathrm{O}$ on molybdenum at $420 \mathrm{~K}$. Neutral molecular hydrogen as well as $\mathrm{H}^{+}$ions were found to be desorbed by ESD. The cross section for neutral desorption was $\sim 2 \times 10^{-17} \mathrm{~cm}^{2}$. Three different binding states were found for $\mathrm{O}_{2}$ adsorption. Neutral 
oxygen molecules and $\mathrm{O}^{+}$ions were liberated by ESD from the most weakly bound state, neutral atomic oxygen desorbed from the next strongest bound state, and no ESD products were observed for the strongest bound state. Desorption cross sections for $\mathrm{O}_{2}$ and atomic oxygen were $\sim 2 \times 10^{-17} \mathrm{~cm}^{2}$ and $\sim 1 \times 10^{-18} \mathrm{~cm}^{2}$ respectively. For water adsorbed on molybdenum three separate binding states wêre:also tound. Âs well as ionic desorption species, neutral $\mathrm{O}_{2}, \mathrm{H}_{2}$ and $\mathrm{H}_{2} \mathrm{O}$ were observed to desorb with cross sections $\sim 10^{-17} \mathrm{~cm}^{2}$ for the most weakly bound state. The next strongest bound state showed neutral atomic oxygen and $0^{+}$desorption with the neutral desorption having a cross section of $\sim 10^{-18} \mathrm{~cm}^{2}$. No ESD products were observed to desorb from the third and strongest bound state. Again, these cross section values for neutral desorption ranging from $\sim 10^{-17} \mathrm{~cm}^{2}$ to $\sim 10^{-18} \mathrm{~cm}^{2}$ agree quite well with all ulles previuusly reported cross section values. To summarize this subsection on ESD of neutrals there are a number of comments that need to be emphasized:

(1) In most of the reported work concerning ESD of neutrals, very little effort had been made to eliminate or minimize the possibility of surface heating caused by the electron bombardment. Consequently, thermal effects may have been responsible (at least in part) For many of the observations. Very few studies were made to determine yield values as a function of bombarding power. If this had been done it might have indicated whether or not the primary mechanism producing the desorption was thermal or true ESD. 
(2) An interesting point to note is that reported cross section values agree quite well with one another - even when comparing results which appear to be thermal induced with those which are more likely to be true ESD effects. In fact, it is important to realize that with similar cross section values for: both thermal and ESD neutral desorption, the number of desorbing neutral particles will increase by the same amount for increases in the bombarding current. In terms of application to high energy devices it makes little difference (for electron energies <500 ev) whether the actual mechanism is thermal or ESD - a similar number of neutral particles may be expected to desorb in either case.

(3) Cross section values for neutral desorption varied from $\sim 10^{-16} \mathrm{~cm}^{2}$ to $\sim 10^{-20} \mathrm{~cm}^{2}$ depending on the condition of the target suiface. For targets with adsorbates in weakly bound states cross sections were as high as $10^{-16} \mathrm{~cm}^{2}$. For clean samples or samples with adsorbates in very strong chemisorbed states, cross sections were as low or lower than $10^{-20} \mathrm{~cm}^{2}$. The cross section detection. limits of all experiments cited here were $\sim 10^{-20} \mathrm{~cm}^{2}$. Cross section values were relatively independent of the adsorbates studied as long as they were in similar states, i.e. weakly bound states, moderately strongly bound states, or very strongly bound states. Also, cross section values for neutral ESD were very insensitive to the type of substrate used as the target material. Again we emphasize that similar apparent cross sections were found even when the primary mechanism appeared to be surface heating. 
(4) Yield values were found which varied from as great as ten molecules/electron to as small as $\sim 10^{-6}$ molecules/electron. These values are of little use in terms of gaining a more complete understanding of electron interactions with surfaces because they are not in a normalized form - that is, they depend on the coverage of the target as well as the cross section of the interactions. Since, in many cases, coverage estimates were not reported, the yield values alone were not too useful. However, it was generally found that, taking coverage estimates into account (when reported or indicated), reported yield values agreed with cross section. results for comparable situations. It is important to note that yield values greater than one from adsorbed gas monolayers must be due to processes other than direct excitation by electrons (ESD).

(5) The mechanism for ESD of ions proposed by Redhead ${ }^{13}$ and Menzel and Gomer ${ }^{12}$ was shown to agree with experiment (Madey, et. al. ${ }^{38}$ ). Menzel ${ }^{25}$ also showed that ESD of neutrals may proceed by an alternate direct excitation process in which no intermediate. ionic state is formed. Menzel's results, which indicated a lower threshold energy needed for neutral ESD as compared to ionic ESD had been shown previously by Isikawal. This was also. indirectly substantiated by Madey, et. al. ${ }^{38}$ and Nishijima and Propst ${ }^{37}$. It appears that for energies lower than $200 \mathrm{eV}$ the primary mechanism for ESD of neutrals is a direct excitation to a neutral anti-bonding. state. For energies greater than $200 \mathrm{eV}$ the question regarding the primary mechanism for neutral ESD has not yet been resolved. 
(6) As regarding high energy devices and especially CTR applications, it was found that the largest cross section values and highest yield values were observed at the beginning of electron bombardment of contaminated or "dosed" surfaces. This is reasonable when one realizes that surfaces of this nature have large coverages of weakly bound adsorbates - just exactly the type of adsorption state which has been found to produce neutral ESD species the most easily.

We will conclude this subsection with the remark that very little has been done to detect neutral ESD in a controlled and quantitative manner. Even less has been done trying to detect neutral ESD using a "single pass - line of sight" technique (see Menzel ${ }^{25}$ ). Since accurate and quantitative detection of ESD of neutrals is much more difficult as compared to ESD of ions this lack of available experimental results is understandable.

C. Electron stimulated desorption of metastable or excited neutrals As discussed previously, ESD of neutrals and excited neutrals was assumed long before any controlled experiments were conducted to detect them. This was particularly true for excited neutrals: because of their very reactive nature excited neutrals could not be easily directly detected except by "line of sight" techniques.

Although they were not directly detected, Redhead 8 (1962) assumed ESD of excited neutrals from the grids of BAGs was the cause of anomalously high collector currents. (ESD of ions was later 
found to be the real cause of this anomaly:) The production of excited neutrals by electron bombardment was considered and allowed for in the mechanistic ESD theories presented by Redhead ${ }^{13}$ and Menzel and Gomer ${ }^{12}$, but it was not until 1966 that some real evidence of the existence of ESD excited neutrals was presented. While studying ESD of neutral CO from single crystal nickel using methods previousily described $(7,11)$ Baker and Péterman ${ }^{18}$ (1966) noticed significant pressure discrepancies between an Omegatron RGA and the two BAGs in the system. They found that, under certain conditions the Omegatron indicated as much as ten times more gas released than did the BAGs. They postulated that this discrepancy was due to an active or excited form of co (probably the $\mathrm{a}^{3} \pi$ excited state) which was readily adsorbed onto the molybdenum grids of the BAGs, but not onto the gold plated structure of the Oneyalsul. They also indlcated that the excited co must have had a lifetime in excess of $1 \mathrm{msec}$ and that it was not readily adsorbed onto the glass surfaces composing their system. The experimental evidence (as analyzed by Baker and Péterman) gave strong indications of ESD of excited neutrals.

As mentioned in an earlier subsection, Redhead ${ }^{20}$ (196.7) studied ESD of CO from molybdenum by collecting. the ESD ions in a. retarding field hemispherical collector. Considering the (at the time) recent results of Baker and Péterman ${ }^{18}$, Redhead decided to see if his apparatus would be sensitive to desorbing excited neutrals. Potentials in his experimental apparatus were adjusted so that no charged particles from either the anode or filament could reach the collector. Photons or excited neutrals reaching 
the collector with sufficient energy could eject electrons at the collector and produce a positive collector current $I^{\star}$. Redhead found and measured such a current, $\left(I^{*}\right)$, for the case co on molybdenum and found it to be comparable in magnitude to the current corresponding to $\operatorname{ESD}$ of ions $\left(\mathrm{I}^{+}\right)$. He aiso found that the variation of $\mathrm{I}^{*}$ was identical to that of $\mathrm{I}^{+}$for changing bombarding electron encrgy and that il exlibited the same threshold. Furthermore; as with $I^{+}, I^{*}$ was observed only when the weakly bound state of CO was adsorbed on molybdenum. Although this experiment could not distinguish between excited neutrals and photons, Redhead (with Baker and Péterman's ${ }^{18}$ results in mind) believed ESD of excited neutrals was the primary cause for $I^{*}$. This was a reasonable assumption for co since there exist, several excited levels of the co molecule with lifetimes in excess of 1 msec and energy $>5 \cdot \cdot e V$.

As Redhead had found previously for the desorption of neutrals $^{13}$, the threshold energy needed for desorption of excited neutrals in the above experiment was the same as that needed for ESD of ions. Since the threshold for ESD of excited neutrals was more easily and accurately measured than had been previously done for ESD of ordinary neutrals it seems reasonable (here) to accept. the proposed mechanism that excited neutrals are produced by an initial transition to an ionized level followed by neutralization via an Auger process with downward transition to the excited level (i.e., metal $+\mathrm{CO}^{\star}$ ).

Time-of-flight techniques were used by clampitt and Newton 27 (I969) to study excited and metastable species produced by electron 
interaction with gas phase molecules. This method was adapted by Clampitt 28 (1969) to detect and study excited neutrals produced by electron impact of surfaces. This method involves: 1) bombardment of a suitable surface with a pulsed beam of electrons (in this case having energies $<50 \mathrm{ev}, 2)$ the desorption products enter a drift tube where the charged species can be easily separated or eliminated, 3) because of their high velocity, photons are easily separated from the excited neutrals at the detector. clampitt found negative. results when looking for excited $\mathrm{H}(2 \mathrm{~S})$ atoms desorbing from metais (with adsorbed $\mathrm{H}_{2}$ ) undergoing electron bombardment. However, when a polyethylene target was used, a signal corresponding to ESD of excited neutral hydrogen atoms was easily detected. clampitt explained his results by reasoning that production of ESD excited neutrals from $\mathrm{H}_{2}$ adsorbed on metals should be small because of the fast resonant de-excitation processes which can occur close to the surface. On the other hand, resonant de-excitation processes should be slow near the surface of an insulator: Since low energy electrons ( $<50 \mathrm{eV}$ ) should easily rupture $\mathrm{C}-\mathrm{H}$ bonds on polyethylene (an insulator) producing excited hydrogen atoms, one should expect them to desorb and be detectable - as was the case in inis experiment.

Newsham and co-workers 41,42 (1972, 1973) looked for ESD of excited neutrals for the case of $\mathrm{CO}$ adsorbed onto single crystal (100) tungsten. They used a time-of-flight technique similar (but more refined and elaborate) to that described by clampitt ${ }^{28}$. Counting techniques were employed to maximize the sensitivity of their instrument. With their instrument they were able to observe 
the behavior of ions and excited neutrals desorbing from the tungsten sample. It was not possible, however, to mass analyze and identify the nature of the ESD excited neutrals.

Their experiments were carefully controlled and a great deal of effort was made to reduce possible complications by studying a simple adsorption system (i.e., $C O$ on clean single crystal tungsten). They found that $\mathrm{O}^{+}, \mathrm{CO}^{+}$, and excited neutrals of an undetermined nature desorbed from tungsten by ESD. It was observed that $\mathrm{CO}^{+}$ and $\mathrm{O}^{+}$ESD signals followed a temperature dependence essentially the same as that found by Menzel ${ }^{25}$ and Yates and King 43 . Furthermore (as also observed by Redhead ${ }^{20}$ ) they found that the excited neutral signal follows the $\mathrm{CO}^{+}$signal, falling to zero at almost exactly the same temperature (as shown in Fig. 7). They also observed the behavior of the $\mathrm{O}^{+}, \mathrm{CO}^{+}$, and excited neutral signal as a function of bombardment time as shown in Fig. 8 . It is also sinown here that the excited neutral signal follows the behavior of the $\mathrm{CO}^{+}$signal very closely. Because of these and other results mentioned in their paper it is proposed that the excited neutrals are $\mathrm{CO}^{*}$ (probably $\mathrm{a}^{3} \pi$ ) and that they, as well as $\mathrm{CO}^{+}$, are released only from the $\alpha_{1}$-CO state on tungsten.

It was also suggested that because of the similarity in behavior of the $\mathrm{CO}^{+}$and excited neutral signal, both ESD species are produced by the same primary mechanism - that is, the excited neutrals are produced by initial excitation to an ionic state as suggested by Redhead ${ }^{20}$. Threshold measurements were made to help substantiate this supposition. Threshold energy values of $15 \pm 1$ and $16 \pm 1 \mathrm{eV}$ were found for ESD of excited neutrals and $\mathrm{CO}^{+} \mathrm{re}^{-}$ 
spectively, in essential agreement as predicted by the above model. To summarize this subsection we would like to point out that:

1) In the papers reviewed in this subsection, essentially no attention has been paid to possible surface heating effects produced by the electron beam because excited neutrals have never been observed to thermally desorb for any situation where excited neutrals have been produced by ESD.

2) In the few experiments conducted which have detected ESD of excited neutrals no cross section values have been measured. Redhead ${ }^{20}$ indicated that excited neutral signals and ion signals were of approximately the same strength, so we might conclude that when excited neutrals are produced the cross section is probably similar to that for ESD of ions.

3) The nature of excited neutrals is such that just detection alone is a difficult task. Wherever direct detection has been accomplished it has not been possible to obtain direct chemical identification of the excited neutrals. So far $c o$ is the only adsorbate (producing ESD excited neutrals) that has been studied, and it is believed that $\mathrm{CO}^{*}$ is the only excited neutral produced for this case.

4) Measurements have shown that the $\mathrm{CO}^{+}$ESD ion signal and the ESD excited neutral $\left(\mathrm{CO}^{*}\right)$ signal behave very much alike. This indicates that, at least for ESD of excited neutrals, the mechanism may follow the same initial excitation to an ionized level as that for ESD of ions. 
III. ESD Using High Energy Primary Beams

We are mainly interested in reviewing what is known about cross section variations with increasing primary energy over the range I to $20 \mathrm{KeV}$. In order to effect an understandable presentation of this topic we find it necessary to digress a bit and include a discussion of low energy ESD (i.e., primary energies less than $500 \mathrm{eV}$ ). Even for this lower energy range (which has been extensively studied) there is a good deal of disagreement in the literature. For the higher energy range there is a very limited amount of material available in the literature, and for this reason neutral and ionic data wili not be separated into subsections. Also, in order to effect a better presentation we have not found it convenient to maintain a chronological sequence in some cases. Finally, there is a fair amount of material available in the literature which concerns high energy ESD using a fixed energy (i.e., combination of ESD and Auger techniques). This material will be separated and covered briefly at the end.

Although the earliest works dealing with ESD considered (to some extent) cross section vs. energy, Moore ${ }^{5,6}(1959,1961)$ was the first to make a carefully controlled study of the behavior of ESD yield up to and somewhat beyond electron energies of $100 \mathrm{eV}$. In his first effort ${ }^{5}$ he studied dissociation of solid sro by electron impact and found that the ESD ionic yield (cross section) for $\mathrm{CO}^{+}$and $\mathrm{O}^{+}$increases to a maximum just beyond the threshold energy and that it only declines slowly for energies greater than $200 \mathrm{eV}$. Later, studying $\mathrm{CO}$ adsorbed on molybdenum he observed a similar behavior for the ESD $\mathrm{O}^{+}$ions as shown in Fig. 9. 
Since Moore's work a large number of ESD studies have been conducted which have made efforts to obtain cross section vs. energy data for energies less than $500 \mathrm{eV}$. For ESD of ions three types of behavior have been observed by various investigators. The first type of cross section vs. energy curve (Fig. 10) exhibits a strong maximum near $100 \mathrm{eV}$ or greater and falls off sharply with increasing electron energy. The position of the maximum has been found to vary from observer to observer and also it is found to vary by the same observer for different ESD ionic species. 9,24,25 The second type of curve (Fig. 11) exhibits a rapid increase in cross section reaching a maximum near $100 \mathrm{eV}$. The cross section then either remains relatively constant or falls off very slowly. with increasing electron energy 6,20 The third type of behavior for ESD of ions is characterized by a rapid increase in the relative cross section with a slow and steady increase with increasing bombarding energy (Fig. 12). This last type of cross section vs. energy behavior has been observed by Nishijima and Propst ${ }^{34,35}$. They claim that this is the actual behavior and that observations reported by others were incorrect, being complicated by collection efficiencies which probably changed with changing electron and ion energy. Considering the lack of agreement between various findings we have consequently analyzed the various experimental procedures employed and we find it difficult to take sides in this issue at this time. For ESD of neutrals the only type of variation which has been found (using energies less than $500 \mathrm{eV}$ ) for cross section vs. energy is exemplified by Fig. 12. That is, ESD of neutrals follows the same type of behavior as that found 
for ions in the third case above. This neutral ESD behavior has been observed by both Menze $1^{25}$ and Nishijima ${ }^{37}$.

As a final remark concerning results of cross section vs. energy ESD data observed for electron energies less than $500 \mathrm{eV}$ we should mention that a number of workers $1,13,23,49$ have found fluctuations which correspond to relative maxima and minima in the cross section curves. These fluctuations have in general been smali. Whether or not they represent some actual structure in terms of electron interaction with the surface or whether they are instrumental artifacts: is still in question.

As mentioned previously there are few well controlled studies of cross section vs. energy for ESD reported in the literature for electron energies. greater than $500 \mathrm{eV}$. Trump and van de Graaff ${ }^{2}$ (1947) and Filosofo and Rostagni ${ }^{3}$ (1949) used a simple diode arrangement to study liberation of ions due to electron bombardment of a metal target in order to gain a better insight into the nature of electrical breakdown in vacuum. They used electrons with energies varying from less than $1000 \mathrm{eV}$ to greater than $70 \mathrm{KeV}$. The type. of cross section vs. energy behavior they observed is shown in. Fig. 13. No arrangement was made to eliminate or minimize gas phase ionization and subsequent collection of these gas phase ions, therefore there is some question regarding how much this effect may have contributed to their results. Filosofo and Rostagni claim that the background pressure has a definite effect on the magnitude and shape of the cross section curve but they indicate that the observed changes in the cross section curve with varying background pressure were too great to be accountable by 
gas phase ionization alone. Perhaps it is possible that the increased pressure also produced increased adsorption of weakly bound surface species which in turn were more easily desorbed as ions by the bombarding electrons. An important point to mention here is that some of the more recent cross section vs. energy studies which have been done for energies greater than $500 \mathrm{eV}$ are in general agreement with this early work. Jüttner ${ }^{31}$ (1970) also used a simple diode device to investigate electrical breakdown in vacuum. As shown in Fig. 14 he observed results considerably different from those found by Trump and van de Graaff. Using electron energies in the range less than 5 to greater than $20 \mathrm{KeV}$ his results show a steadily increasing ion desorption efficiency with increasing electron energy. Although the general shape of the curve remained the same, he found that the magnitude of the ion signal increased for increased background pressures. In the three studies just mentioned it is very difficult to analyze the results in a simple fashion because of the numerous processes which may have had an effect on the measured collector ion current (i.e., ESD, gas phase ionization, collection efficiency variations, effects of secondary electron bombardment on other surfaces, etc.).

$\operatorname{Hartman}^{10}$ (1963) in his study concerning ESD from the grids of BAGs found that $\mathrm{ESD}$ of $\mathrm{O}^{+}$exhibited a steadily increasing cross section even up to $1000 \mathrm{eV}$ electron bombarding energy. Since the collection efficiency (of the BAG used for the detector) as a function of electron energy was not well known, and $x$-rays were shown to make some definite contribution to the collector current, these results may be somewhat questionable. Dawson ${ }^{21}$ (1967) 
studied outgassing of glass by electron bombardment as discussed in the section on neutral desorption. Using neutral detection only, he found $\mathrm{O}_{2}$ to desorb from glass with a steadily increasing efficiency with increasing electron energy (up to $1000 \mathrm{eV}$ ). as. shown in Fig. 15. We have stated earlier that we find it hard to eliminate the possibility of thermal effects contributing to some extent to his results.

Lichtman and McQuistan ${ }^{17}$ (1965) using a relatively sophisticated system for studying ESD with a very low current density primary electron beam found a steadily increasing cross section for ESD of $\mathrm{H}^{+}$ions from stainless steel for electron energies varying from about 500 to $6000 \mathrm{eV}$ as shown in Fig. 16. Since it is very likely that the collection efficiency varied markedly because of the way potentials were adjusted with increases in the electron energy, these results are questionable in regard to their general accuracy. The minor variations in the cross section vs. energy curve shown as a series of relative maxima and minima in in Fig. 16 may be an experimental artifact or it may indicate some real structural features concerning the strength of interaction with increasing electron energy. This question has not yet been resolved in favor of either argument.

Fischer and Mack ${ }^{16}$ (1965) investigated neutral ESD in regard to design problems involved in high energy machines (as discussed earlier). They bombarded OFHC copper with electrons varying in energy from 0 to $10 \mathrm{KeV}$ and observed the desorption efficiency for hydrogen and carbon monoxide as indicated in Fig. 17. Their results show a cross section which increases with increasing energy 
in a very irregular way. The irregularity is quite different from any observations reported by others for ESD cross section variations. As mentioned previously, the high electron current densities used here, coupled with the fact that only neutral desorption was measured makes it difficult to analyze these results without including possible surface heating effects.

Garwin, et al ${ }^{26}$ (1968) made a particularly careful study concerning ESD of neutral CO. Using aluminum as a target, they found the cross section vs. energy relationship (electron energies 0 to $10 \mathrm{KeV}$ ) for neutral ESD of adsorbed $\mathrm{CO}$ as shown by curve 2 in Fig. 18. The shape of this curve, is reminiscent of a typical gas phase ionization cross section curve - only broadened. They also showed (using different isotopes of $\mathrm{CO}$ ) that for some cases ali: of the desorbing co does not come from the surface alone, but that there can be a contribution from $\mathrm{CO}$ absorbed in the bulk. If care is taken to eliminate the absorbed CO, the ESD curve for the adsorbed $\mathrm{CO}$ is that shown by curve 2 in Fig. 18. If absorbed CO is present in the bulk near the surface the behavior observed is that shown by curve 1 in Fig. 18. The position of the high energy tail observed in curve 1 seemed to indicate the extent to which $C O$ was present in the bulk near the surface. By bombarding the target with high current density beams of varying energy prior to adsorption and ESD measurements the high energy tail could be moved to higher and higher energies. The conclusion drawn is that ESD of neutral CO desorbing only from surface adsorbed CO exhibits a cross section vs. energy relationship similar but 
broadened compared to gas phase ionization cross section curves: Since only neutrals were detected here, the possibility (as was the case with ESD of ions) of collection efficiencies changing with increasing electron energy is small. Furthermore, electron beam current densities were kept small enough so as to minimize any possible surface heating effects.

A number of other workers have used electron energies greater than $200 \mathrm{eV}$ to study ESD, but (for this group) usually only one or two primary beam energies were employed in each report. McCraken, et al ${ }^{19}$ (1967) studied gas evolution from stainless steel using electron bombardment. Using $600 \mathrm{eV}$ electrons and with an: Omegatron RGA to monitor ESD of neutrals they found cross sections which varied from $\sim 10^{-16}$ to $\sim 10^{-20} \mathrm{~cm}^{2}$. Initially the cross sections, were quite high $\left(\sim 10^{-16} \mathrm{~cm}^{2}\right)$ decaying to much smailer values $\left(\sim 10^{-20} \mathrm{~cm}^{2}\right)$ after several hours of continuous bombardment. Although measured cross section values were found to be relatively independent of beam current densities (.1 to $200 \mathrm{\mu A} / \mathrm{cm}^{2}$ ) some of the results reported in this paper would certainly appear to be thermal effects rather than true ESD (as discussed earlier).

Studying ESD of $\mathrm{O}_{2}$ on $\mathrm{W}(100)$ using Auger techniques, Musket ${ }^{36}$ (1970) obtained a value of $21.5 \times 10^{-20} \mathrm{~cm}^{2}$ for the absolute cross section for ESD of oxygen. A primary beam having an energy of 1365. eV was used here. This cross section value was in fair agreement with other ESD studies done investigating $\mathrm{O}_{2}$ on single crystal tungsten (using primary beams with energies $\leq 300 \mathrm{eV}$ ) 22,43 . Watts, et al 47 (1974) also studied. $O_{2}$ adsorbed on $w(100)$ using 
Auger techniques. His main objective was to show the magnitude of beam effects in changing surface populations in relationship to Auger analysis. He found that the primary beam $(2.5 \mathrm{KeV})$ used for this study caused considerable Esb of the adsorbed oxygen with an observed cross section of $\sim 10^{-19} \mathrm{~cm}^{2}$ at both $300 \mathrm{~K}$ and $77 \mathrm{~K}$.

Goldstein ${ }^{45}$ (1973) used Auger techniques to investigate electron beam effects on a polycrystalline Beo surface. The surface carbon (from adsorbed $C O$ ) was found to gradually disappear with continued electron bombardment if an $\mathrm{O}_{2}$ background pressure of $\sim_{10^{-7}}$ to $10^{-6}$ Torr was maintained. It was concluded here that the primary ESD species was $\mathrm{CO}^{+}$. A value of $\sim 2 \times 10^{-20} \mathrm{~cm}^{2}$ (independent of primary beam energy from 400 to $1200 \mathrm{eV}$ and beam current densities of .8 to $4.0 \mathrm{~mA} / \mathrm{cm}^{2}$ ) was measured for the ESD cross section. The observations made seem to indicate that true ESD was the primary desorption mechanism. Margoninski 48 (1975) investigated ESD of oxygen from the (111) face of a single crystal germanium sample. Using $1.5 \mathrm{KeV}$ electrons he measured the total ESD cross section to be $\sim 6 \times 10^{-20} \mathrm{~cm}^{2}$. This was the first published paper containing an ESD cross section value from an elemental semiconducting sample.

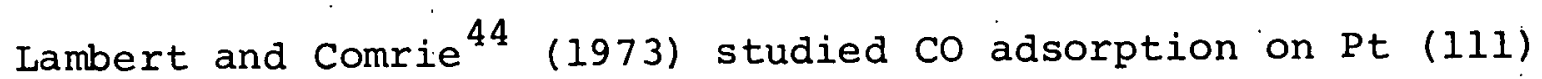
using Auger analysis. The primary aim of this study was to determine the extent to which the electron beam affected the surface under study. Of particular. interest were ESD effects. Using an electron primary beam of $1.5 \mathrm{KeV}$ they measured an ESD total cross section value of $\sim 5.0 \times 10^{-18} \mathrm{~cm}^{2}$ for this system (CO on 
Pt (111)). Of significant importance was their study concerning the relative effects of the primary electrons compared to the effects produced by the secondary electrons returning through the adsorbed layer. They found the total ESD cross section for the primary electrons $(1.5 \mathrm{KeV})$ to be $22.5 \times 10^{-19} \mathrm{~cm}^{2}$, while that for the secondaries was $22.5 \times 10^{-18} \mathrm{~cm}^{2}$. This clearly shows that the majority of ESD for high energy primary beams is due to the secondary electrons. This explains why all studies of ESD using high energy primary beams have shown cross sections to be comparable to those obtained at lower energies (i.e., 100 to $300 \mathrm{ev)}$.

To summarize this section we would like to emphasize these final remarks:

1) There is a great deal of disagreement concerning the general shape of the cross section vs. energy curve for ESD. Not only is there disagreement in the high energy range (greater than $500 \mathrm{eV}$ ) where little work has been done - there is considerable disagreement for the lower energy range (less than $500 \mathrm{eV}$ ) where much work has been done.

2) In general, there have been two types of behavior found for high energy ESD. Some have found the cross section to increase steadily with increasing energy as shown by Fig. 16, while.others have found the behavior to be more like a broadened gas phase ionization cross section curve (like that shown by curve 2, Fig. 18). which drops off slowly for higher energies. Based on our recent research we are inclined to favor the second type of behavior as the correct one. 
3) Although absolute cross section values vary from observer to observer, adsorbate to adsorbate, substrate to substrate, as well as with changes in energy - this variation is of no greater magnitude than for the variation in cross section found at low energies (less than $200 \mathrm{eV}$ ) as tabulated by Madey and Yates ${ }^{39}$. Furthermore, the cross section values are similar in magnitude as those found at low energies (i.e., total cross sections of $\sim 10^{-1.8} \mathrm{~cm}^{2}$, and ionic cross sections of $\sim 10^{-20} \mathrm{~cm}^{2}$ are commonly found) and it has been found in general, for a given system, that the cross sections for ESD do not vary by more than a factor of four for the energy range 50 to $50,000 \mathrm{eV}$.

4) Lambert and comrie 44 have shown that low energy secondaries are the main cause for ESD when high energy primary beams are used. This explains to some degree why both types of curves mentioned in comment two are so much different than gas phase ionization cross section curves - even though the mechanism for ESD and GPI are considered to be similar 12,13 . Because of the dependence of secondary electron yield with angle of incidence of the primary beam, energy of the primary beam, type of surface, etc. one may argue in favor of either type of cross section vs. energy curve as mentioned in comment two above. For this reason more care must be taken when obtaining and reporting results concerning. high energy ESD. 
IV. Conclusion

The general conclusions one can reach concerning the present status of knowledge concerning ESD is that there is fairly uniform agreement concerning the qualitative aspects and considerable disagreement concerning the quantitative aspects. Thus, it seems agreed that ESD involves the direct quantum interaction of an electron with an dasorbed molecule or molecular complex. Through a Frank-Condon transition, the adsorbed molecule is raised to an anti-bonding state. The dissociation process then gives rise to the desorption of neutral, excited or ionized fragments. Quantitatively, cross section values obtained for these processes range from $10^{-16} \mathrm{~cm}^{2}$ to less than $10^{-20} \mathrm{~cm}^{2}$. In addition, there is as yet considerable disagreement concerning the shape of the cross section vs. bombarding electron energy curve. The most work and the closest agreement exists for electron-induced ion desorption at a bombarding energy of about $100 \mathrm{eV}$. For many weakly bound adsorbed molecules, the cross section is about $10^{-18} \mathrm{~cm}^{2}$. There is very little work reported on neutral desorption and practically no direct measurements. There is even less data on ESD as a function of bombarding electron energy in the range above $500 \mathrm{eV}$. Since these last two areas are the ones of major concern to the CTR program; it is clear that these are the areas where additional work must be done. Since there is widespread agreement concerning the fundamental mechanisms involved, efforts can concentrate on obtaining quantitative data from systems of interest to the CTR program. 
We would like to gratefully acknowledge the support of ERDA, Materials and Radiation Effects Branch, Division of Magnetic Fusion Energy, Contract No. E(11-1)-2425. 


\section{ELECTRON STIMULATED DESORPTION}

\section{REFERENCE LIST}

1. Isikawa, Y., "The Desorption of the Adsorbed Gases by the Impact of Slow E'lectrons (I)" Rev. Phys. Chem. Jap. 16, 83

(1942); "The Desorption of the Adsorbed Gases by the Impact of S1nw Fiertrons (II)" Rev. Phys. Chem. Jap. 16, 117 (1942).

2. Trump, J. G. and van de Graaff, R. J.,"The Insulation of High Voltages in Vacuum" J. Appl. Phys. 18, 327 (1947).

3. Filosofo, I. and Rostagni, A., "On the Liberation of Ions by Electron Bombardment" Phys. Rev. 75, 1269 (1949).

4. Plumlee, R. H. and Smith, L. P., "Mass Spectrometric Study of Solids I. Preliminary study of Sublimation Characteristics of Oxide Cathode Materials" J. Appl. Phys. 21, 811 (1950).

5. Moore, G. E., "Dissociation of Solid Sro by Impact of Slow. Electrons" J. Appl. Phys. 30, 1086 (1959).

6. Moore, G. E., "Dissociation of Adsorbed CO by Slow Electrons" J. Appl. Phys. 32, 1241 (1961).

7. Degras, D. A. ; Péterman, L. A., and Schram, A., "Investigation of Gas-Solid Interactions by Electron Bombardment" from the 9 th National Symposium of the AVS, p. 497, 1962.

8. Redhead, P. A., "The Variation in the 'x-ray limit' of HotCathode Gauges" Vacuum 12, 267 (1962).

9.. Redhead; P. A., "The Effects of Adsorbed Oxygen on Measurements with Ionization. Gauges" Vacuum 13, 253 (1963).

10. Hartman, T. E., "Anomalous Residual Currents in the Ultrahigh Vacuum Use of Bayard-Alpert Ionization Gauges" Rev. Sci. Instr. 34, 1190 (1963). 
11. Péterman, L. A., "Gas Desorption Efficiency Under Electron Bombardment" Nuovo Cimento Suppl. 1, 601 (1963).

12. Menzel, D. and Gomer, R., "Desorption from Metal Surfaces by Low-Energy Electrons." J. Chem. Phys. 4l1, 3311 (1964).

13. Redhead, P. A., "Interaction of Slow Electrons with Chemisorbed Oxygen" Can. J. Phys. $\underline{42}, 886$ (1964).

14. Redhead, P. A., "Desorption of $\mathrm{CO}$ and $\mathrm{O}^{+}$from Polycrystalline Mo Surfaces by Slow Electron Impact" Appl. Phys. Letters $\underline{4}$, 166 (1964).

15. Kendall, B. R. F., "Current-Induced Gas Evolution from Electron Multipliers" J. Vac. Sci. Technol. 2 , 1 (1965).

16. Fischer, G. E. and Mack, R. A., "Vacuum Design Problems of High Current Electron Storage Rings" J. Vac. Sci. Technol. 2. 123 (1965).

17. Lichtman, D. and McQuistan, R. B., "Slow Electron Interaction With Adsorbed Gases" Prog. in Nuclear Energy (Series IX), Vol. 4. part 2 (1965).

18. Baker, F. A. and Péterman, I. A., "Pressure Discrepancy in the Desorption of Carbon Monoxide by Low-Energy Electron Bombardment" J. Vac. Sci. Technol. 3, 255 (1966).

19. 'McCracken, G. M., Barton, R. S. and Dillon, W., "ElectronInduced Desorption of Gas From Stainless Steel Surfaces." Nuovo Cimento Suppl. $\underline{5}, 146$ (1967).

20. Redhead, P. A., "Electron Impact Desorption of Carbon Monoxide from Tungsten" Nuovo Cimento Suppl. $\underline{5}, 586$ (1967).

21. Dawson, P. H., "Outgassing of Glass by 100 to 1000 Volt Electron Bombardment" Nuovo Cimento Suppl. $\underline{5}, 612$ (1967).

22. Zingerman, Ya. P. and Ischuk, V. A., "Investigation of the Process of Sorption of Oxygen on (100) and (110) Faces of Tungsten Single Crystal Using Electron-Stimulated Desorption Effect" Sov. Phys. - Solid State 9, 623 (1967). 
23. Zingerman, Ya. P. and Ischuk, V. A., "Mechanism of ElectronStimulated Desorption of Oxygen From Surface of Tungsten" Sov. Phys. - Solid state 9 , 2368 (1968).

24. Coburn, J. W., "The Dissociative Desorption of Carbon Monoxide from Tungsten" Surface Sci. 11, 61 (1968):

25. Menze1, D., "Desorption, Dissociation, and Ionization of Adsorbed Particles by. Slow Electrons: Carbon Monoxide on Tungsten" Ber. Bunseges. Physik Chem. 72, 591 (1968).

26. Garwin, E. I., Hoyt, E. W. and Jürow, J., "Electron-Induced Desorption of Gases from Aluminum" Proc. 4th Nat. Vac. Conf. p. 131 (1968).

27. Clampitt, R. and Newton, A. S., "Metastable Species Produced by Electron Excitation of $\mathrm{N}_{2}, \mathrm{H}_{2}, \mathrm{~N}_{2} \mathrm{O}$ and $\mathrm{CO}_{2}$ " J. Chem. Phys. 50, 1997 (1969).

28. Clampitt, R., "Fast $\mathrm{H}(2 \mathrm{~S})$ Atoms from Electron-Beam Excitation of Polyethylene" Polymer 10, 721 (1969).

29. Klopfer, A., "Sauerstoffdesorption Von Wolfram Durch Elektronenstoss" (Oxygen Desorption of Tungsten by Electron Impact) Vacuum Teknik 19, 1 (1970); "Desorption Durch Elektronenbeschuss Von Wolfram Mit Adsorbierten Wasser" (Desorption of Water from Tungsten by Electron Bombardment) Vacuum Teknik 19, 37 (1970); "Wasserstoffdesorption Von Wolfram Durch Elektronenstoss" (Hydrogen Desorption of Tungsten by Electron Impact) Vacuum Teknik 19, 167 (1970).

30. Klopfer, A., "Desorption Durch Elektronenbeschuss Von Molybdän mit Adsorbierten Gasen: $\mathrm{H}_{2}, \mathrm{O}_{2}, \mathrm{H}_{2} \mathrm{O}$ " (Desorption by Electron Bombardment of Molybdenum with the Adsorbed Gases: $\mathrm{H}_{2}, \mathrm{O}_{2}$ ' $\left.\mathrm{H}_{2} \mathrm{O}\right)$ Surface Sci. 20,129 (19.70).

31. Jüttner, Von B., "Erzeugung Positives Ionen Durch Beschuss Adsorbierten Gasschichten Auf Metallen Mit KeV - Elektronen" (Production of Positive Ions by Bombarding Gases Adsorbed on Metals with KeV Electrons) Exp. Tech. der Phys. 18, 45 $(1970)$. 
32. Menzel, D., "Inelastic Interactions of Slow Electrons with Adsorbed Particles" Angew. Chem. Int. Edit. Engl. 9, 255 (1970).

33. Redhead, P.A., "Ion Desorption by Electron Bombardment; Relation to Total and Partial Pressure Measurement" J. Vac. Sci. Technol. I, i82 (1970).

34. Nishijima, M. and Propst, F. M., "Apparatus for the Study of the Electron Impact Desorption of Ions and Neutrals from solid Surfaces", J. Vac. Sei. Techmol.

35. Nishijima, M. and Propst, F. M., "Kinetics of Electron Impact Desorption of Ions and Neutrals from Polycrystalline Tungsten" J. Vac. Sci. Technol. 7, 420 (1970).

36. Musket, R. G. , "Auger Electron Spectroscopy Study of ElectronImpact Desorption". Surface Sci. Letters 21, 440 (1970).

37. Nishijima, M. and Propst, F. M. , "Electron Impact Desorption of Ions from Polycrystalline Tungsten" Phys. Rev. B2, 2368 (1970).

38. Madey, T. E., and Yates, J. T., Jr., Kinq, D. A. and Ụhlaner, C. J., "Isotope Effect in Electron Stimulated Desorption: Oxygen Chemisorbed on Tungsten" J. Chem. Phys. 52, 5215 (1970).

39: Madey, T. E. and Yates, J. T., Jr., "Electron-Stimulated Desorption as a Tool for studies of Chemisorption: A Review" J. Vac. Sci. Technol. 8 , 525 (1971).

40. Leck, J. H. and Stimpson, B. P., "Desorption from Gas Covered Surfaces by Electron Impact: A Review of the Subject" J. Vac. Sci. Technol. $\underline{9}, 293$ (1972).

41. Newsham, I. G., Hogue, J. V. and Sandstrom, D. R., "Electron Stimulated Desorption of Excited Neutrals: CO on W" J. Vac. Sci. Technol. $\underline{9}, 596$ (1972).

42." Newsham, I. G. and Sandstrom, D. R., "Time-of-Flight Analysis of Ions and Excited Neutrals Released by ESD of CO on (100) $W^{*} "$ J. Vac. Sci. Technol. 10, 39 (1973). 
43. Yates, J. T., Jr. and King, D. A., "Chemisorption of CO on Tungsten (100): Combined Flash Desorption and Electron Stimulated Desorption Study. II" Surface Sci. 38, 114 (1973).

44. Lambert, R. M. and Comrie, C. M., "The Role of Primary and Secondary Electrons in.Electron Induced Desorption and Dissociation: CO on Pt(111)" Surface Sci. 38, 197 (1973).

45. Goldstein, B., "Electron-Beam Induced Reduction of Carbon Concentration on BeO and Its Effects on Secondary Electron Emission" Surface Sai. 39, 261 (1973).

46. Fabel, G. W. Cox, S. M. and Lichtman, D., "Photodesorption From 304 stainless Steel" Surface Sci. 40, 571 (1973).

47. Watts, G. D., Jones, A. R. and Hopkins, B. J., "An Auger Electron Spectroscopy Study of the Electron Stimulated Desorption of Oxygen from a Tungsten (100) Surface" Surface Sci. $\underline{45}, 705$ (1974).

48. Margoninski, Y., "An AES Study of Electron-Beam Stimulated Desorption of oxygen from a Semiconductor surface" Phys. Tetters 54A, 391 (1975).

49. Madden, H. H. " "Threshold Measurements in Electron Stimulated Desorption : Oxygen on Nickel" Bull. Am. Phys. Soc. 20, 854 (1975).

50.: Menzel, D., "Electron Stimulated Desorption: Principles and Recent Developments" Surface Sci. 47, 370 (1975). 


\section{ESD - Figure Captions}

Fig. 1: Relative desorption efficiency of $\mathrm{H}_{2}$ with increasing bombarding electron energy. A threshold energy for. ESD of 8 to $10 \mathrm{eV}$ is clearly indicated. Taken from the work done by Isikawa. (Adapted from Ref: 1)

Fig. 2: Relative $\mathrm{H}_{2}$ desorption efficiency as a function of bombarding electron energy. A number of relative maxima and minima are clearly shown for energies 0 to $60 \mathrm{eV}$. Taken from work done by Isikawa. (Adapted from Ref. 1)

Fig. 3: Transient response of the ESD neutral CO signal following repopulation at reduced bombarding current density. Taken from the work of Garwin, Hoyt, and Jurow. (Adapted from Ref. 26)

Fig. 4: Effect of the base pressure on the equilibrium electron desorption. Taken from work by Garwin, Hoyt, and Jurow. (Adapted from Ref.26)

Fig. 5: Relative desorption efficiency of neutral Co near. the ESD threshold energy (for two different runs). Co on tungsten. Taken from Menzel's work (1968). (Adapted from Ref. 25) 
Fig. 6: Comparison of the variation with electron energy of the total desorption cross section (open circles) and the ion desorption cross section (solid curve) for $\mathrm{O}_{2}$ on tungsten. Both sets of data were normalized at $V_{e}=150 \mathrm{eV}$. Taken from the work of Nishijima and Propst. (Adapted from Ref. 37)

Fig: 7: Dependence of excited neutral, $\mathrm{CO}^{+}$, and $\mathrm{O}^{+}$signals on temperature during a slow (approximately $20 \mathrm{~min}$. ) temperature sweep. Note the similarity in behavior of the excited neutral and $\mathrm{CO}^{+}$signals. Taken from work by Newsham and Sandstrom. (Adapted from Ref. 42)

Fig. 8: Dependence of excited neutral, $\mathrm{CO}^{+}$, and $\mathrm{O}^{+}$signals on time during electron bombardment at $10 \mu \mathrm{A}$. Note the similarity between the excited neutral and $\mathrm{Co}^{+}$ curves. Taken from work done by Newsham and Sandstrom. (Adapted from Ref. 42)

Fig. 9: Effect of electron energy on $\mathrm{O}^{+}$ion emission for two sets of sample-system conditions, as observed by Moore. (Adapted from Ref. 6)

Fig. 10: Ionic ESD cross section vs. energy curve of the first type (for electron energies up to $500 \mathrm{eV}$ ), showing a strong maximum near $150 \mathrm{eV}$.

Fig. 11: Ionic ESD cross section vs, energy curve of the second type (for electron energies up to $500 \mathrm{eV}$ ), showing a maximum near $100 \mathrm{eV}$ with some decrease in cross. section for increasing electron energy. 
Fig. 12: Ionic ESD cross section vs. energy curve of the third type (for electron energies up to $5.00 \mathrm{eV}$ ), showing a sharp rise in cross section with a subsequent slower rise past $100 \mathrm{eV}$.

Fig. 13: Ion desorption efficiency as a function of bombarding electron energy for energies up to $160 \mathrm{KeV}$. Taken from the paper by Trump and van de Graaff. (Adapted from Ref. 2)

Fig. 14: High energy cross section data showing dependence of the desorption efficiency with changes in the base pressure of the system. Taken from Jüttner's work. (Adapted from Ref. 31)

Fig. 15: Dependence of the initial oxygen outgassing rate of the bombarding electrons (for a particular glass sample, using a current density of $2 \times 10^{-3} \mathrm{~A} / \mathrm{cm}^{2}$ ). Taken from the work done by Dawson. (Adapted from Ref. 21)

Fig. 16; Relative inn desoxption cffieiency fur $\mathrm{H}^{+}$(from a stainless steel target) as a function of bombarding electron energy. Taken from the paper by Lichtman and McQuistan. (Adapted from Ref. 17)

Fig. 17: Desorption rate of $\mathrm{H}_{2}$ and $\mathrm{CO}$ from a copper target as observed in a spectrometer by Fischer and Mack. This relative cross section curve shows unusual structure near $500 \mathrm{eV}$. (Adapted from Ref. 17)

Fig. 18: Surface (circles) and bulk (triangles) electron desorption energy dependence for $\mathrm{CO}$. The high energy tail for the $\mathrm{CO}^{16}$ data comes from $\mathrm{CO}$ adsorbed near the surface. Taken from the paper by Garwin, Hoyt, and Jurow. (Adapted from Ref. 26) 


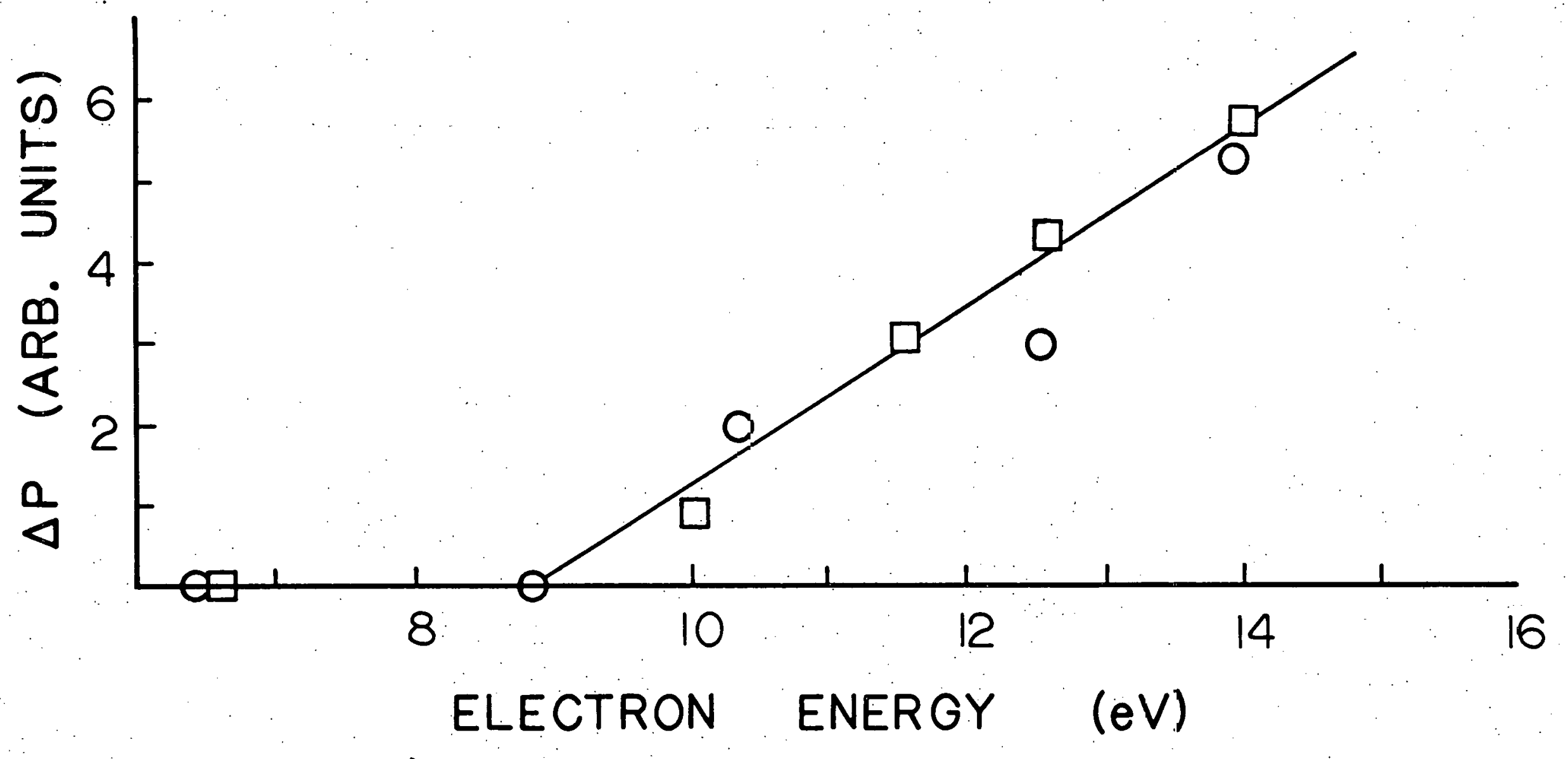

FIG, 1 


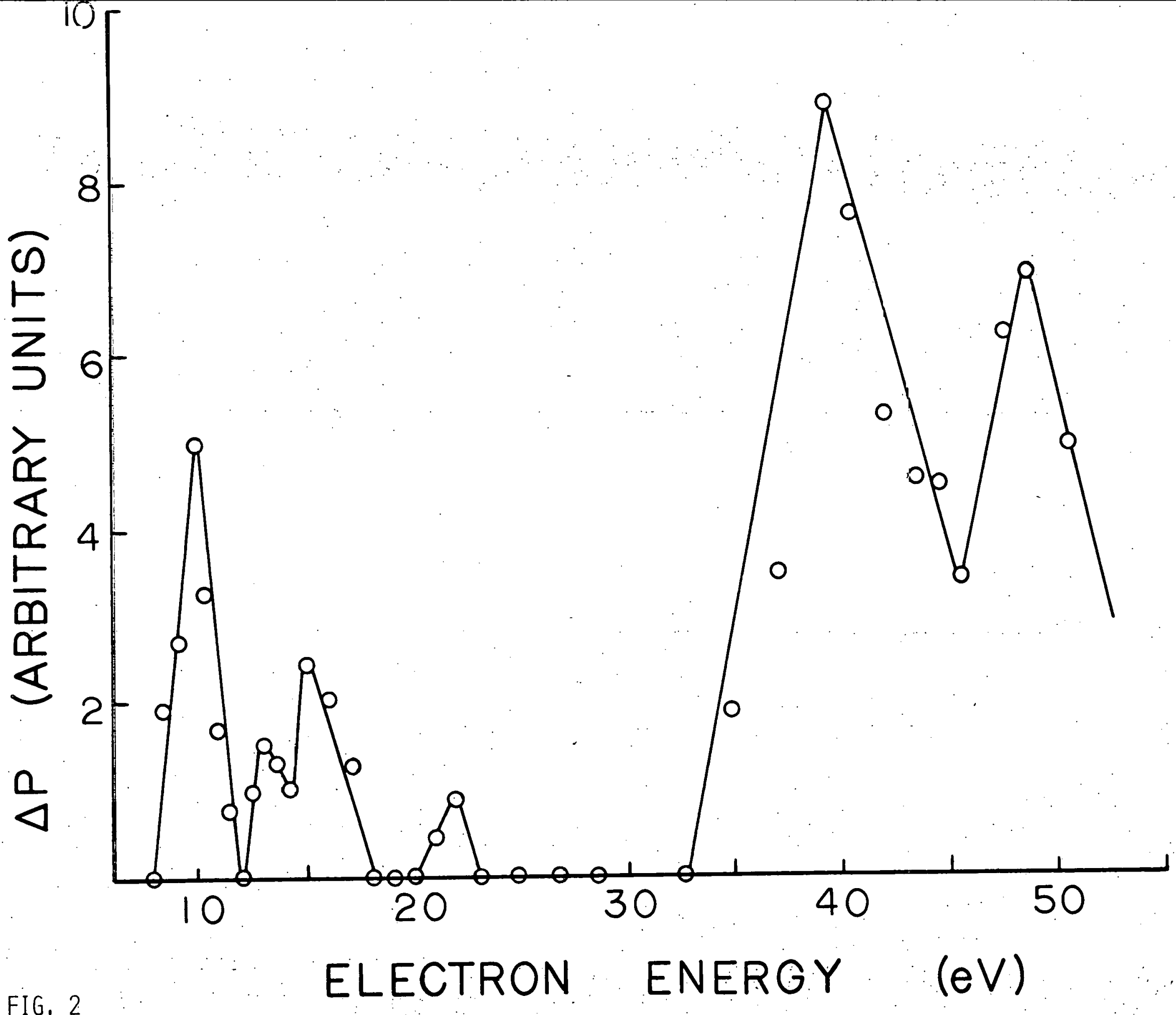




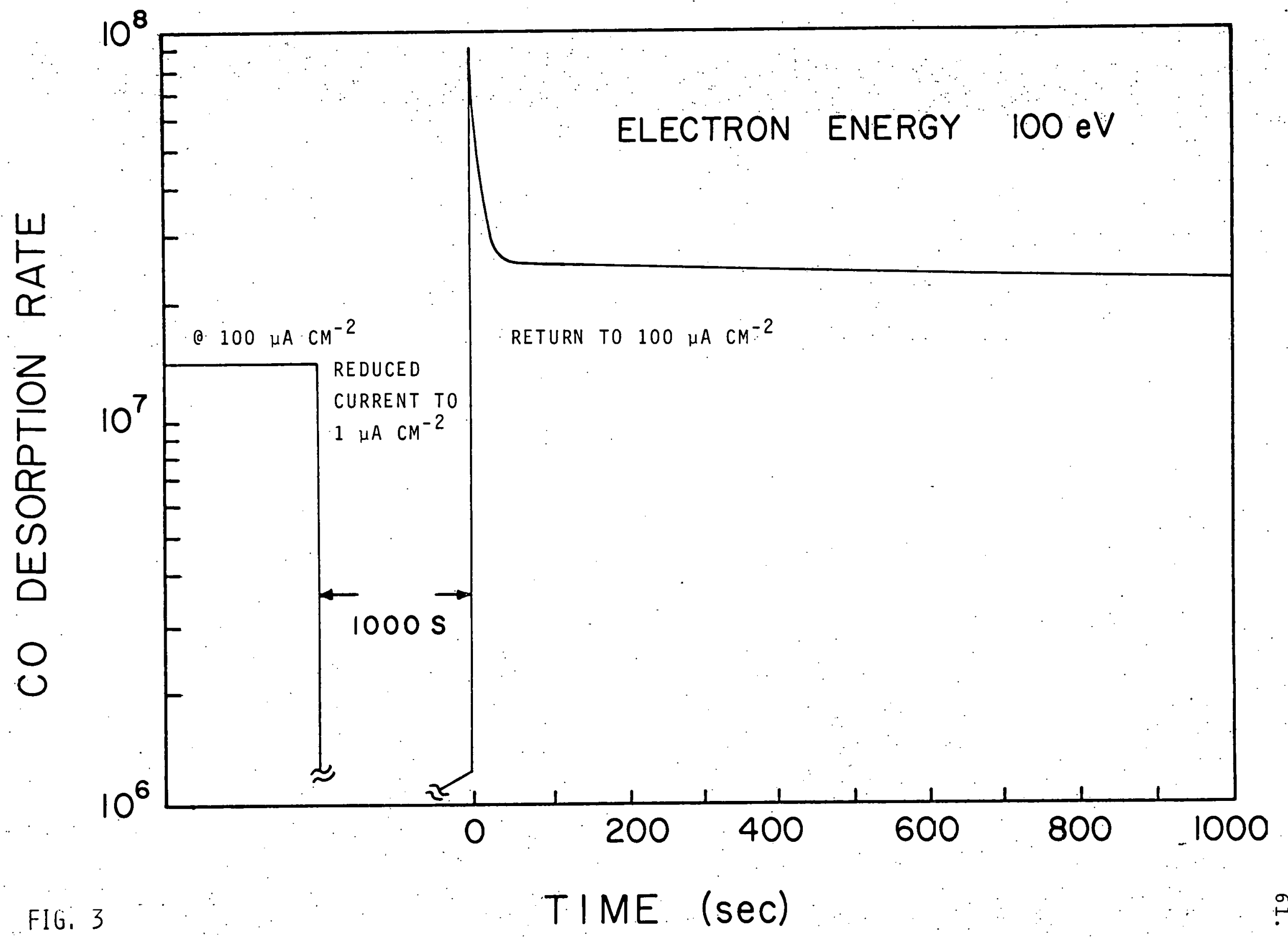




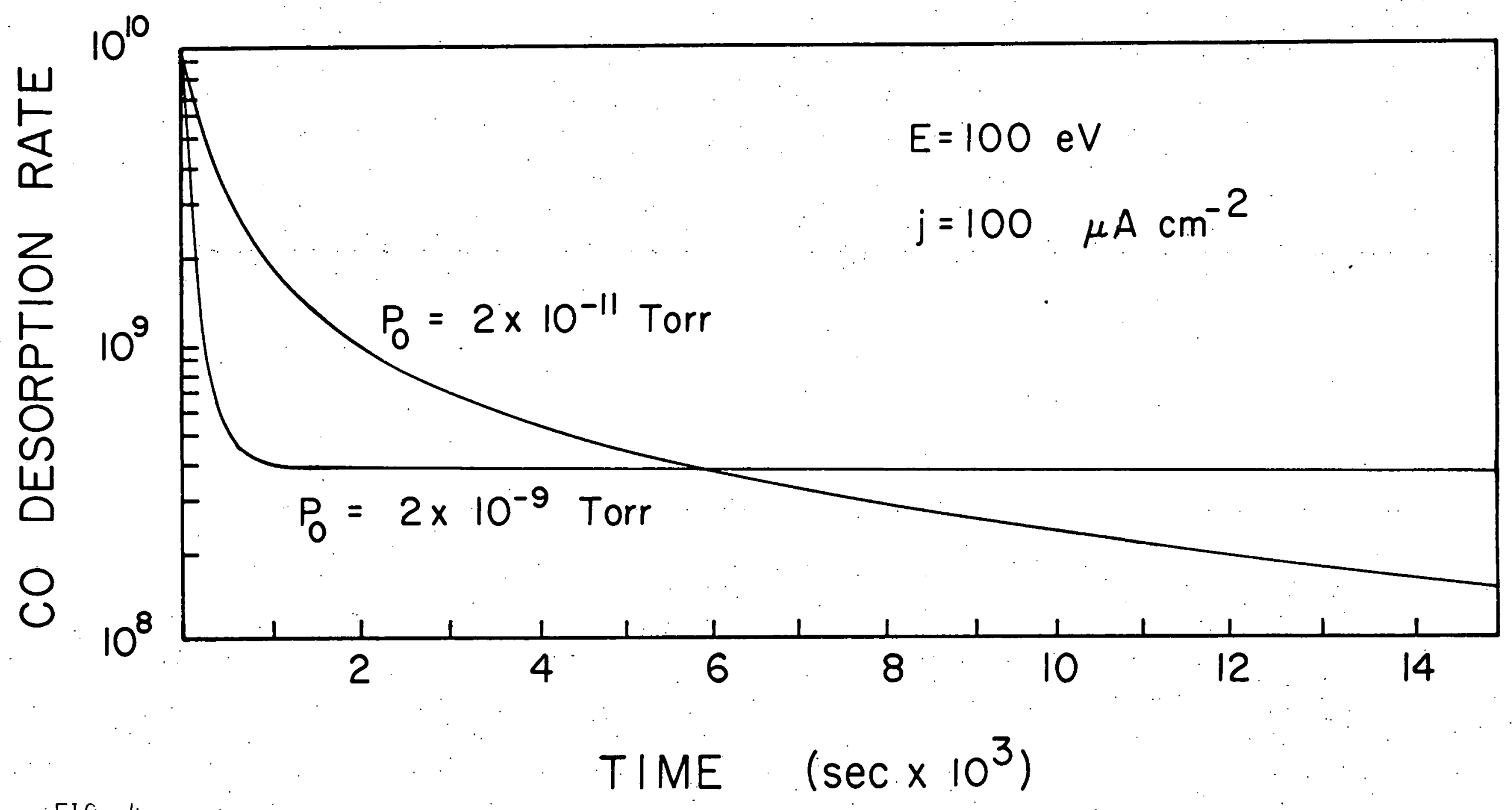

FIG. 4 


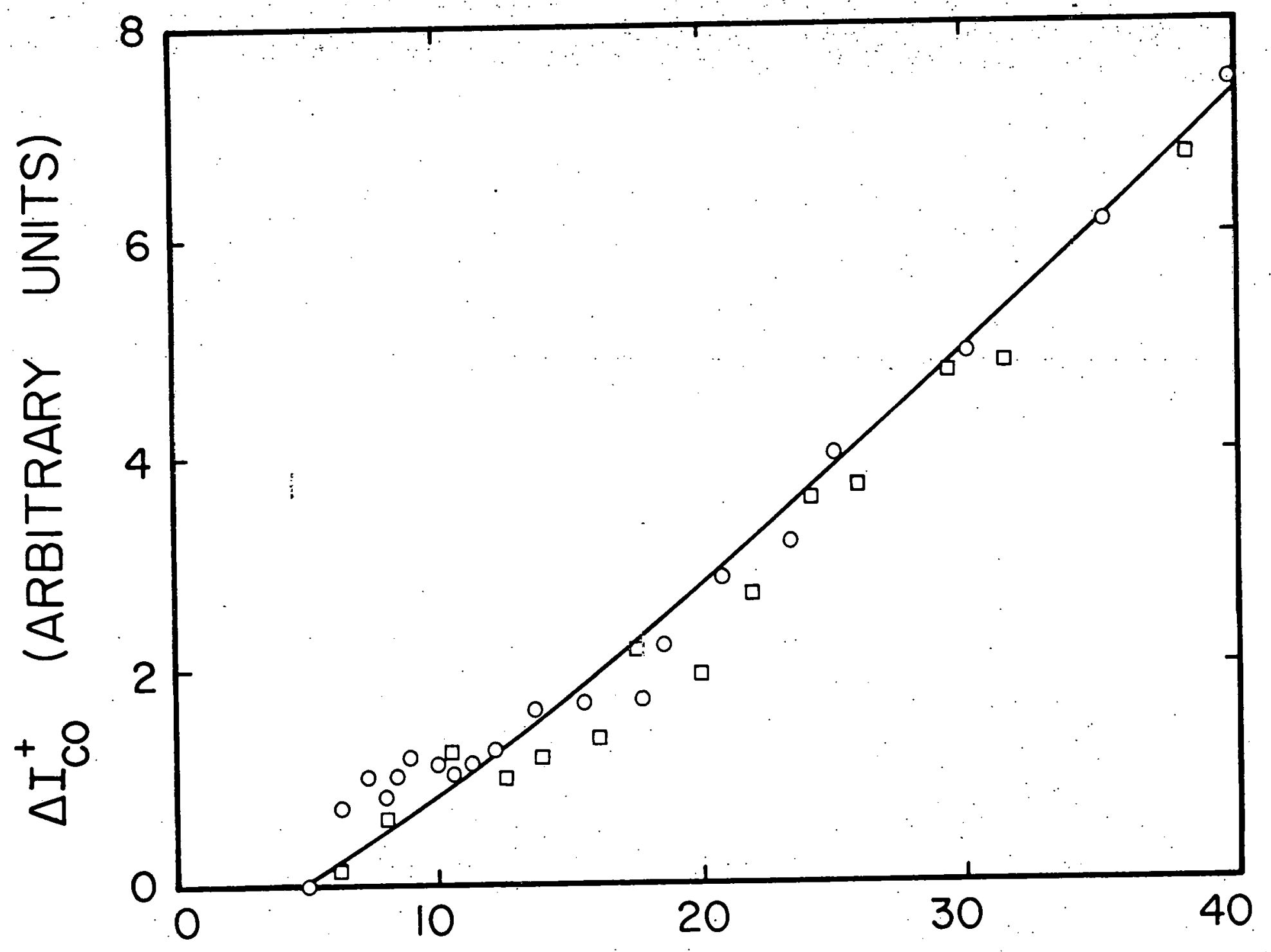

FIG. 5

ELECTRON ENERGY (eV) 


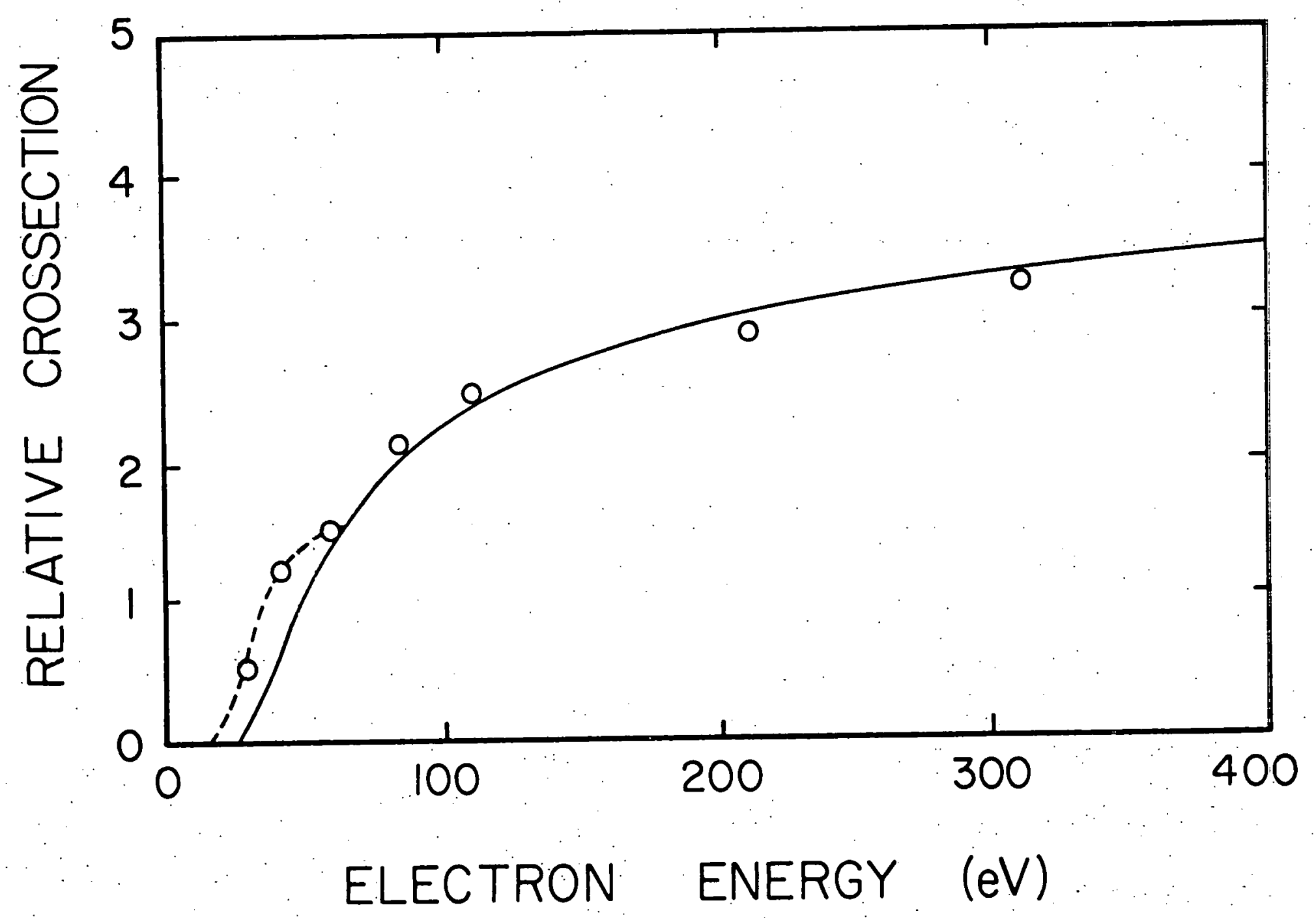

FIG, 6 


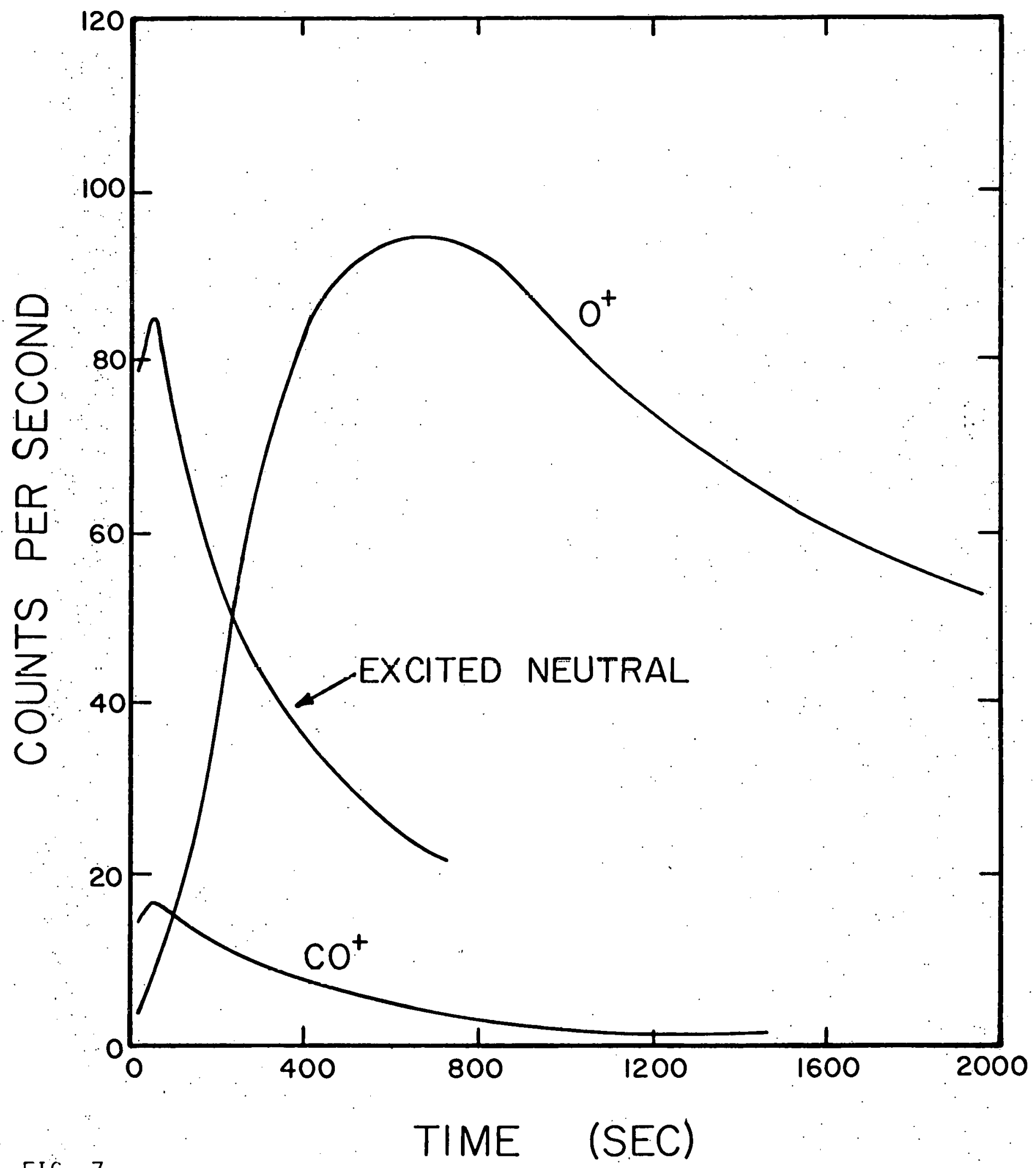

FIG. 7 


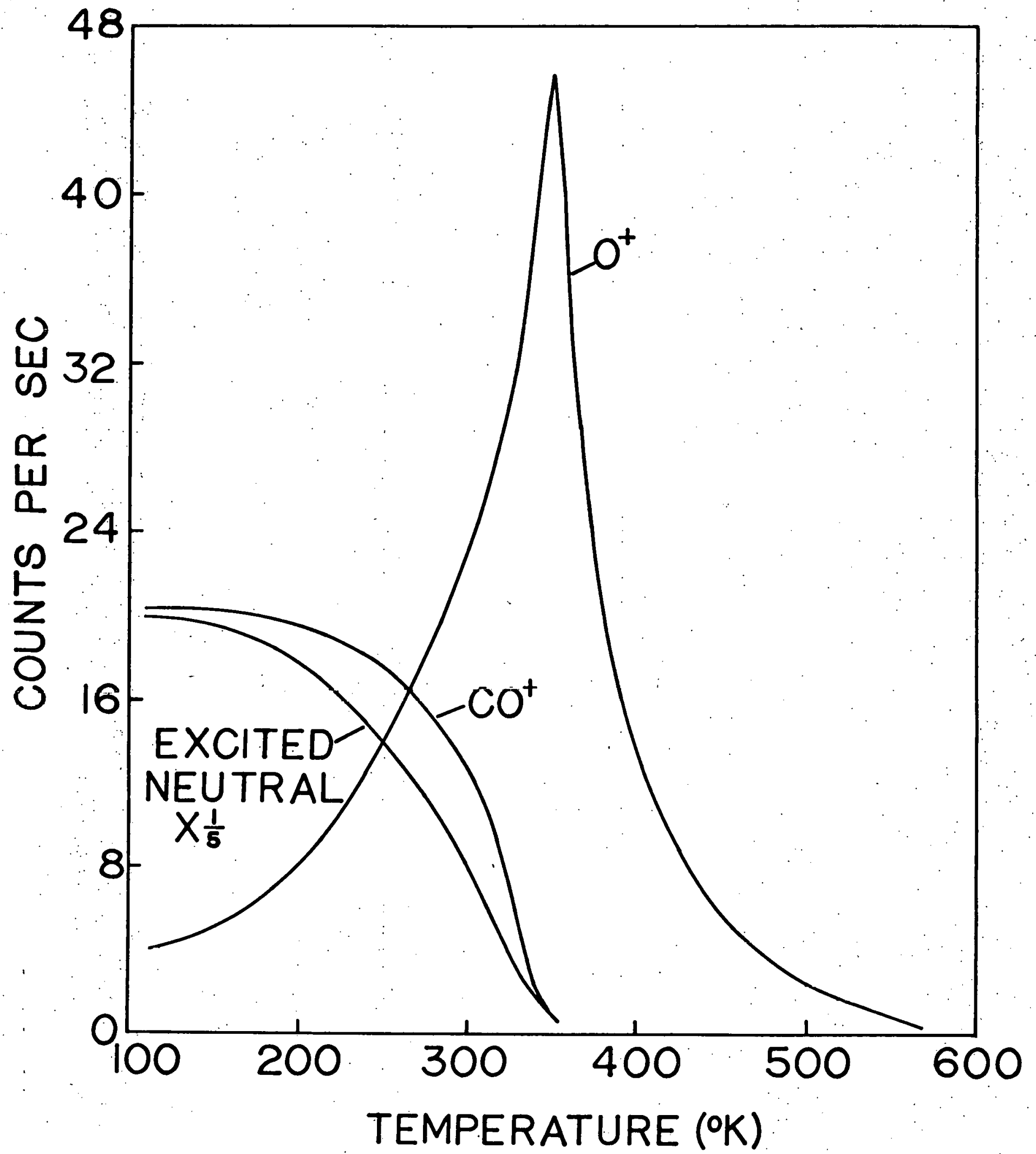

FIG. 8 


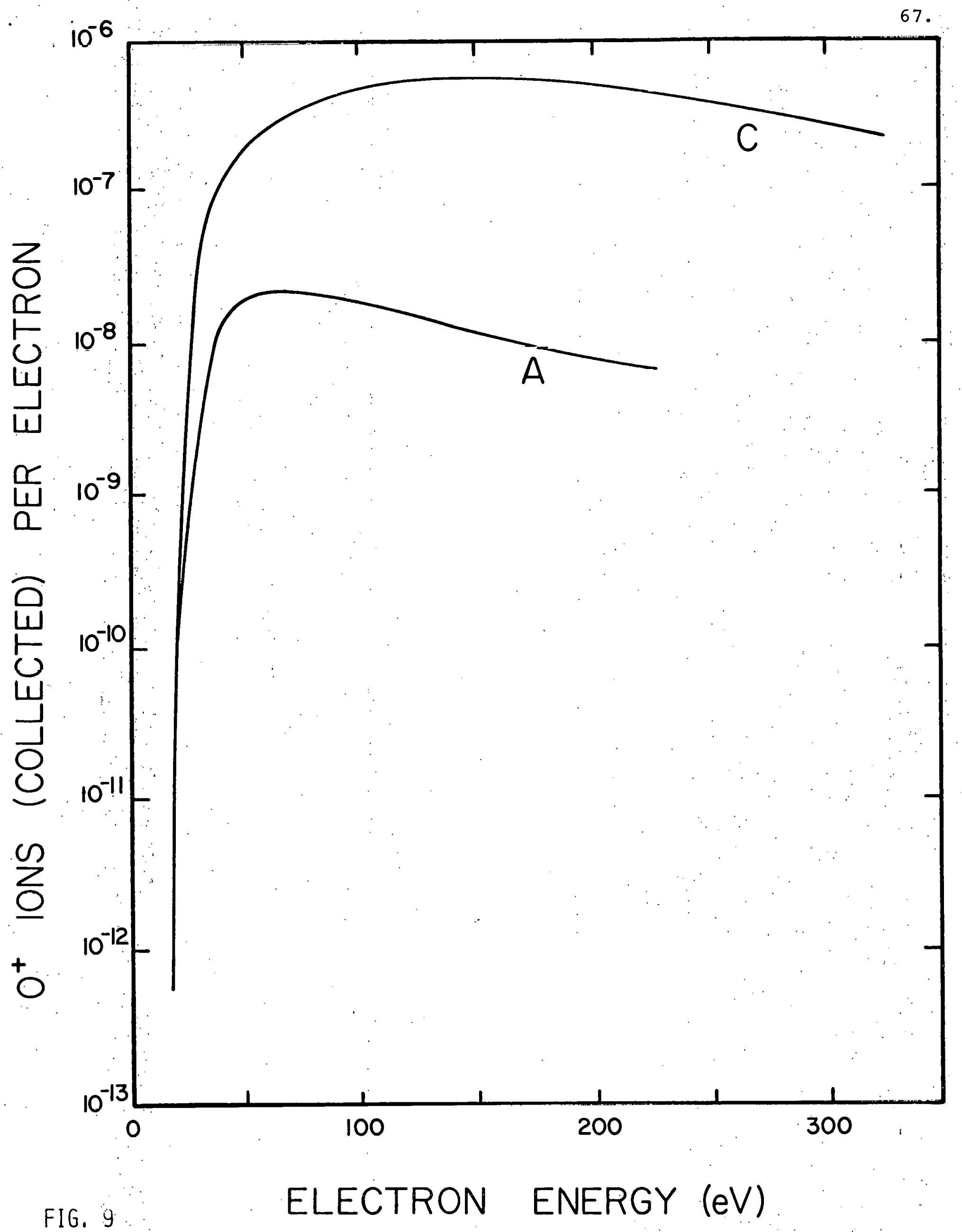




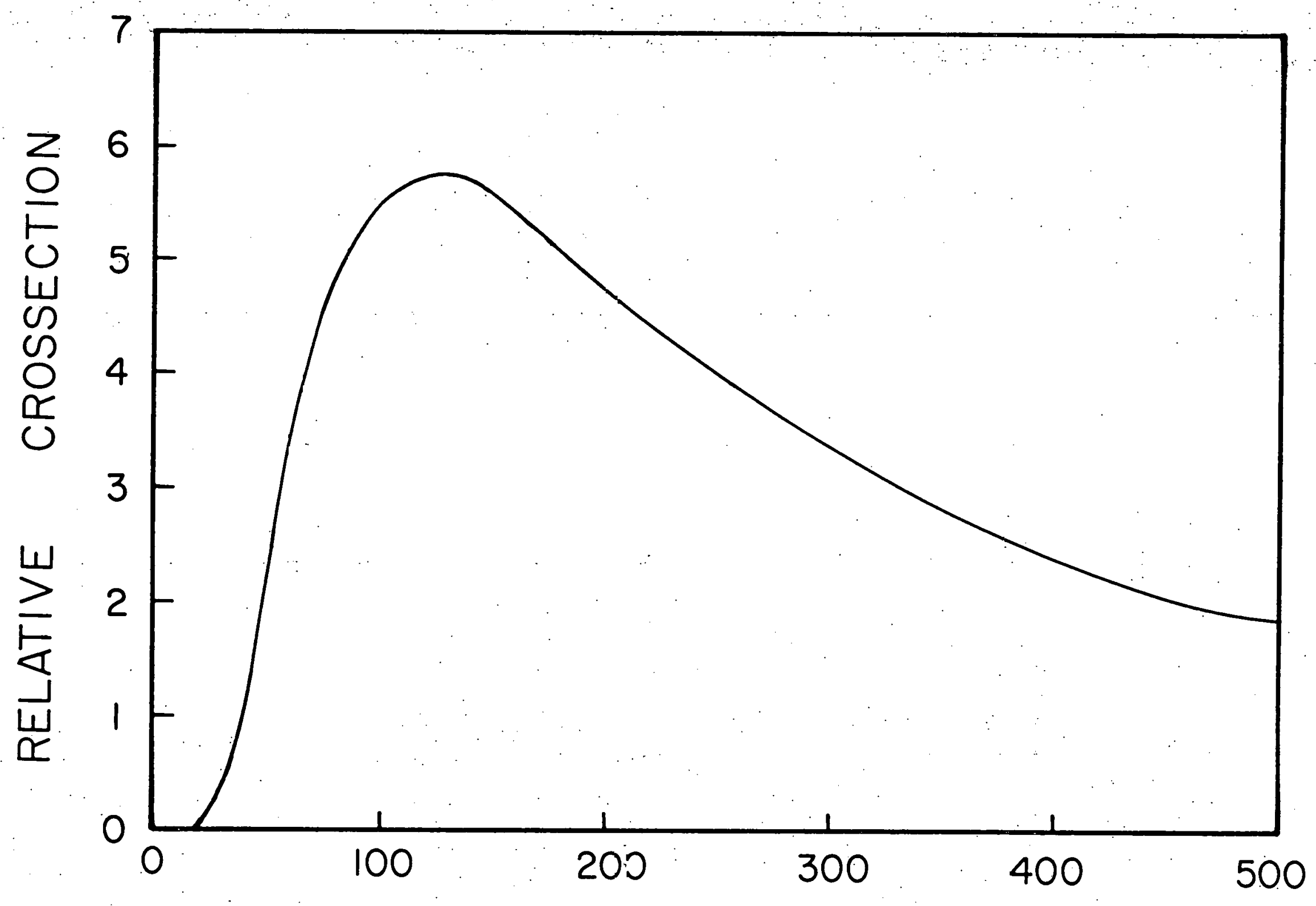

FIG, 10

ELECTRON ENERGY (eV) 


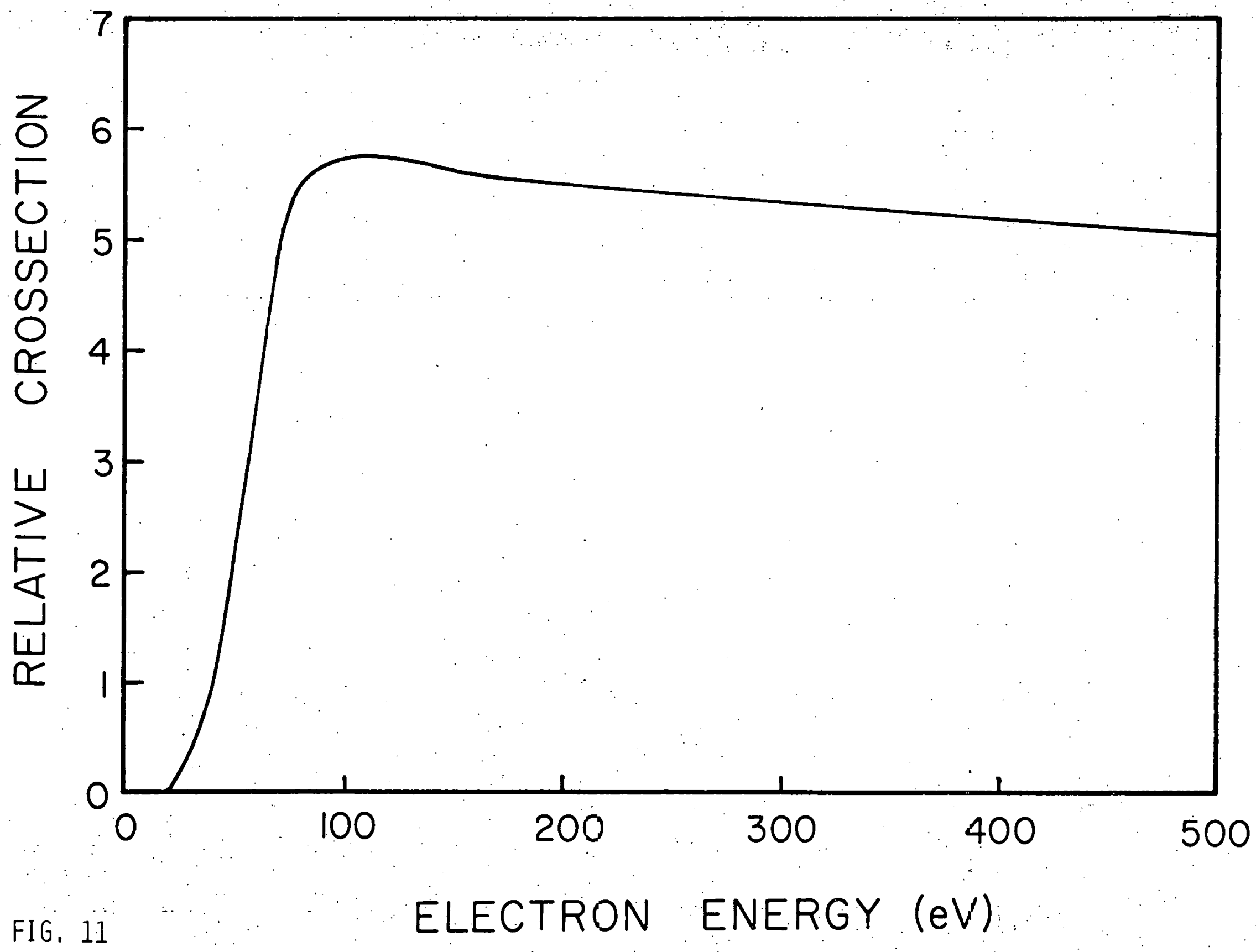




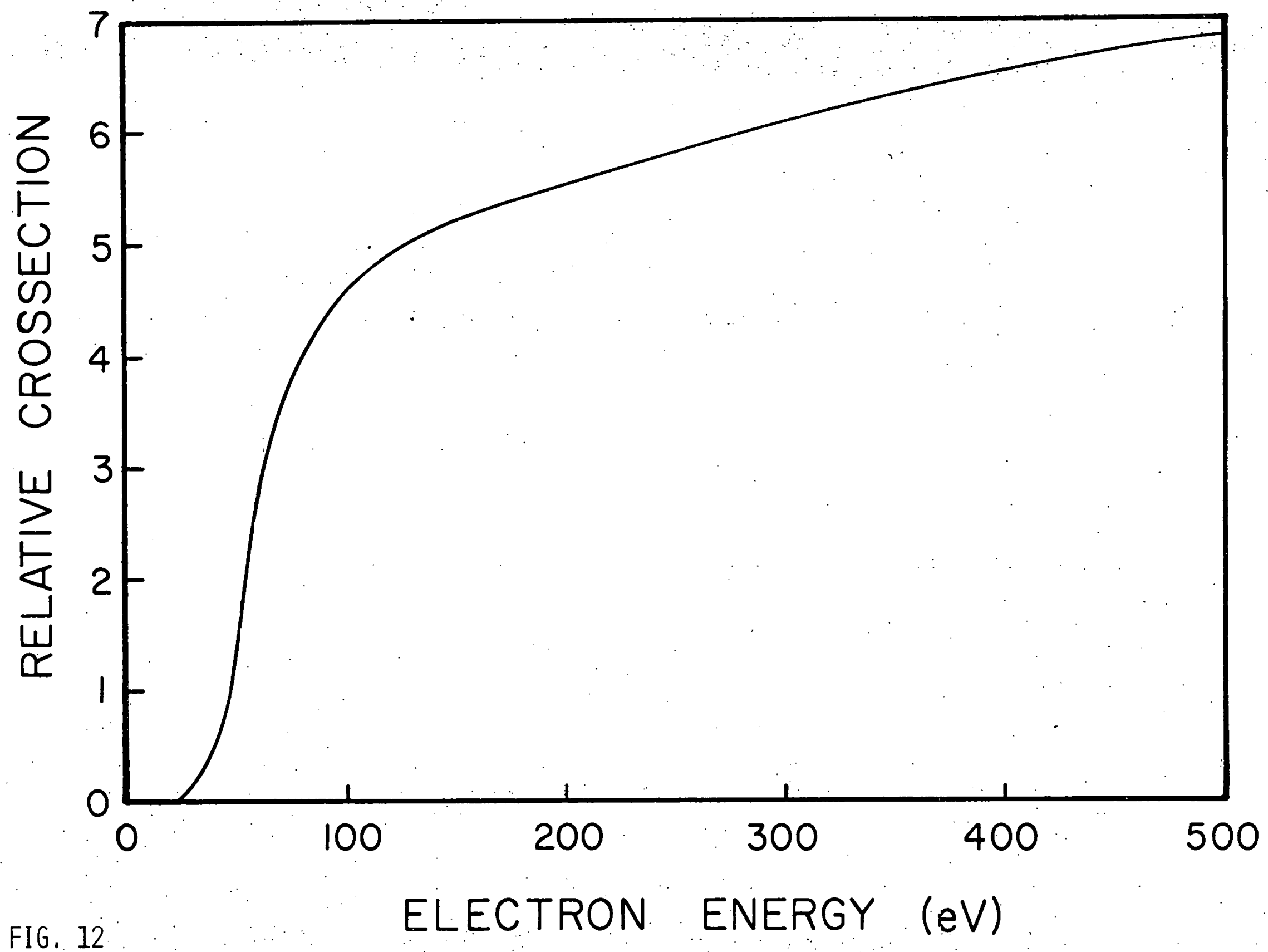




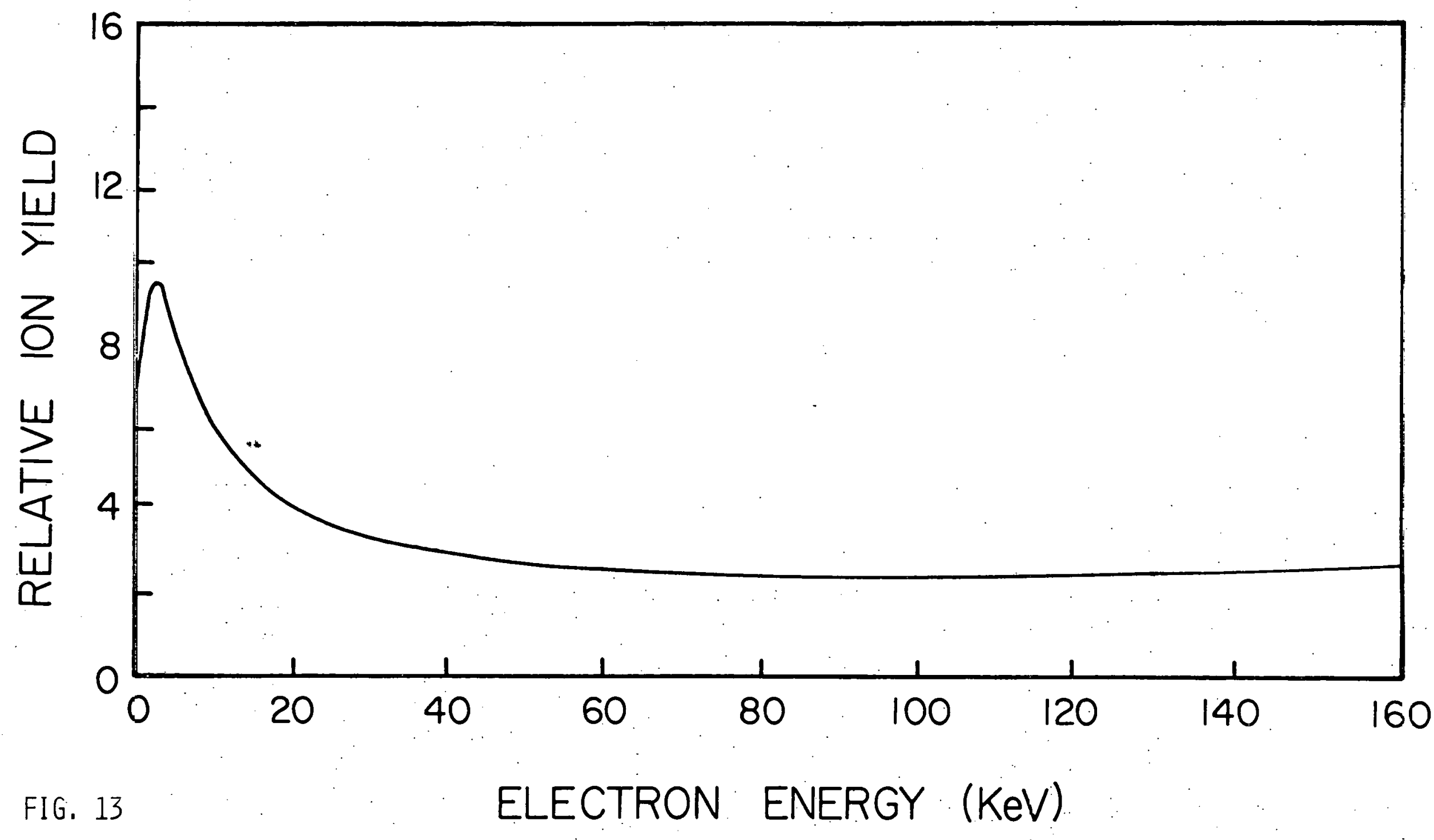




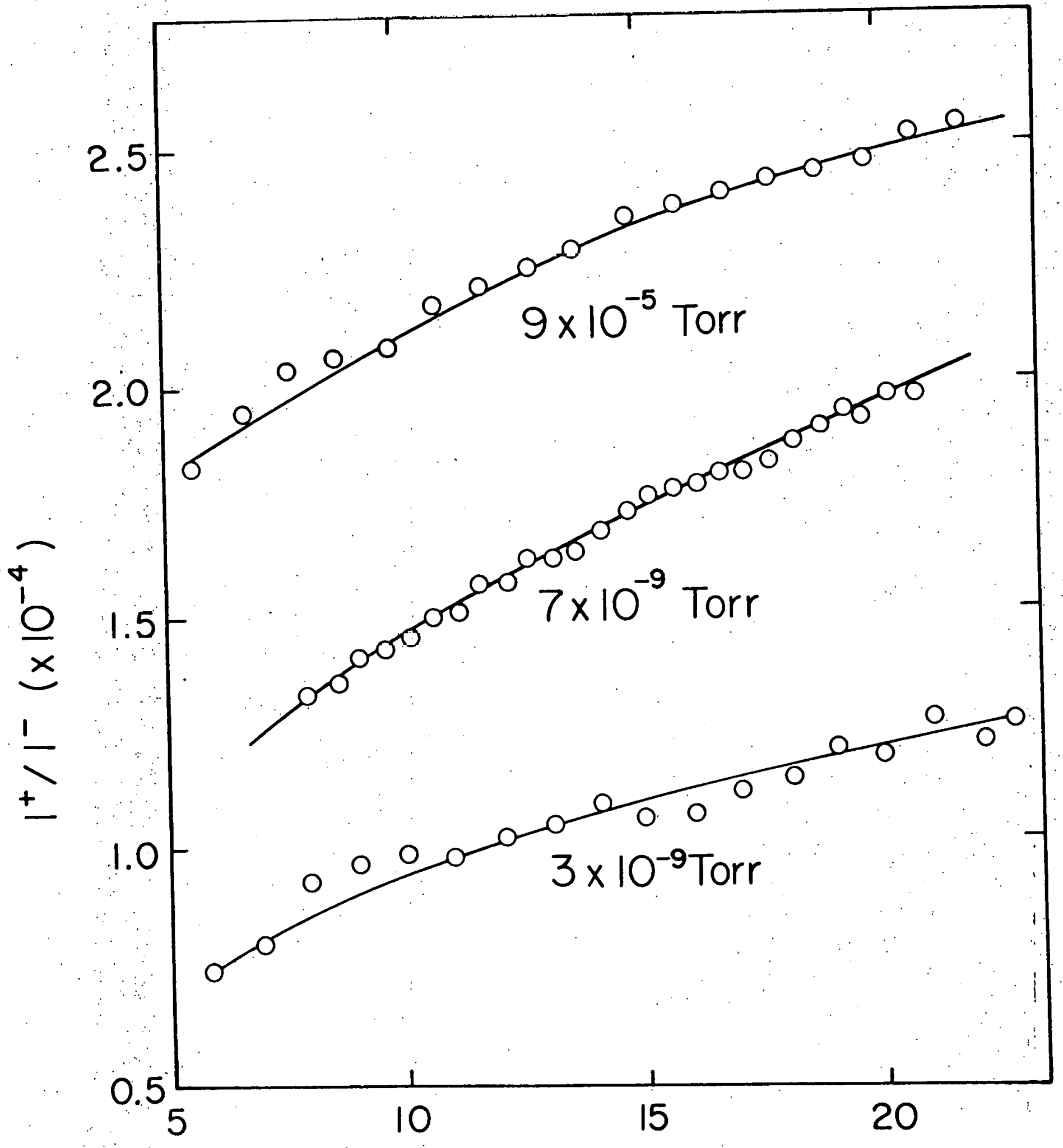

ELECTRON ENERGY (KeV)

FIG. 14 


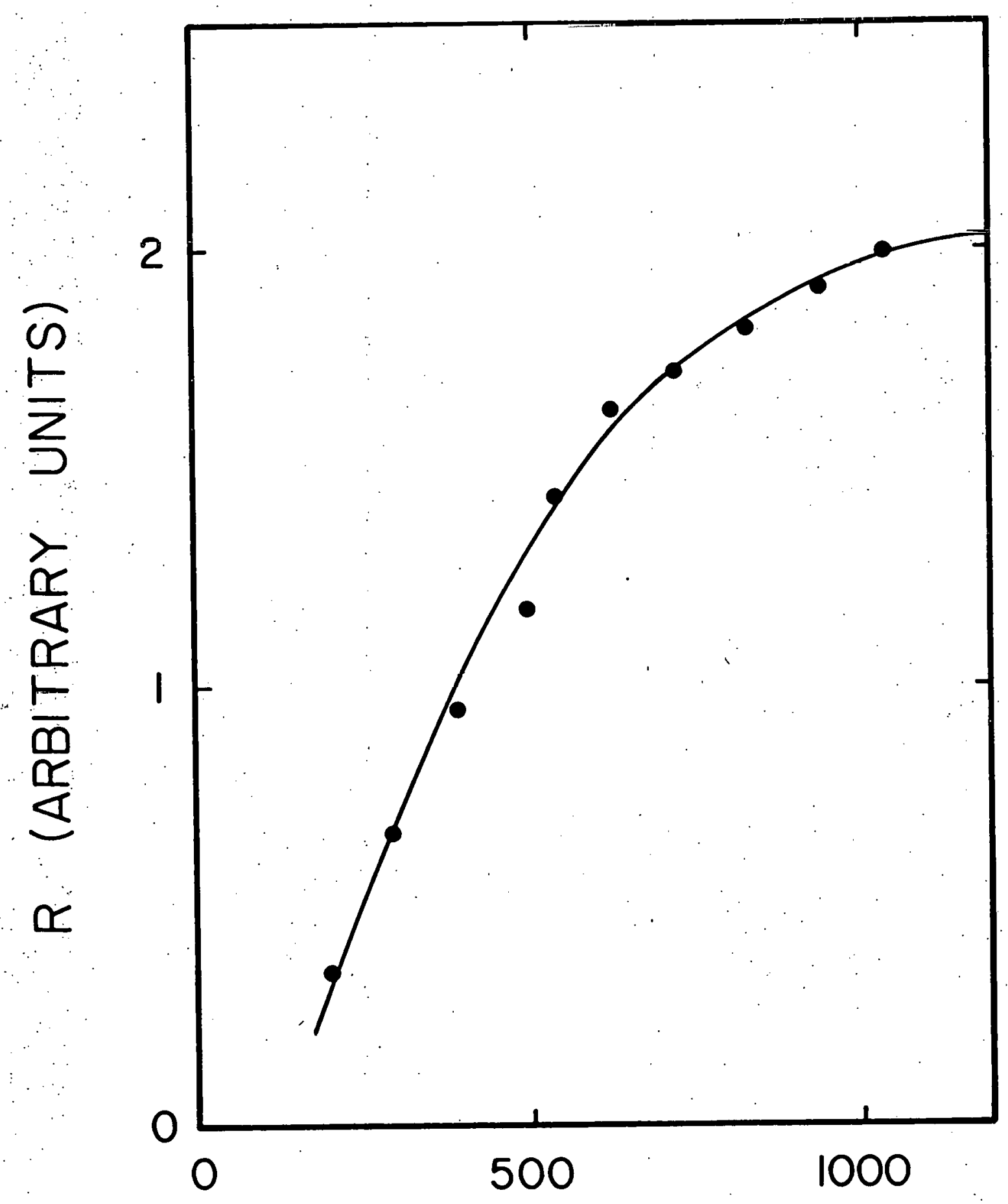

FIG $: 15$ ELECTRON ENERGY (eV) 


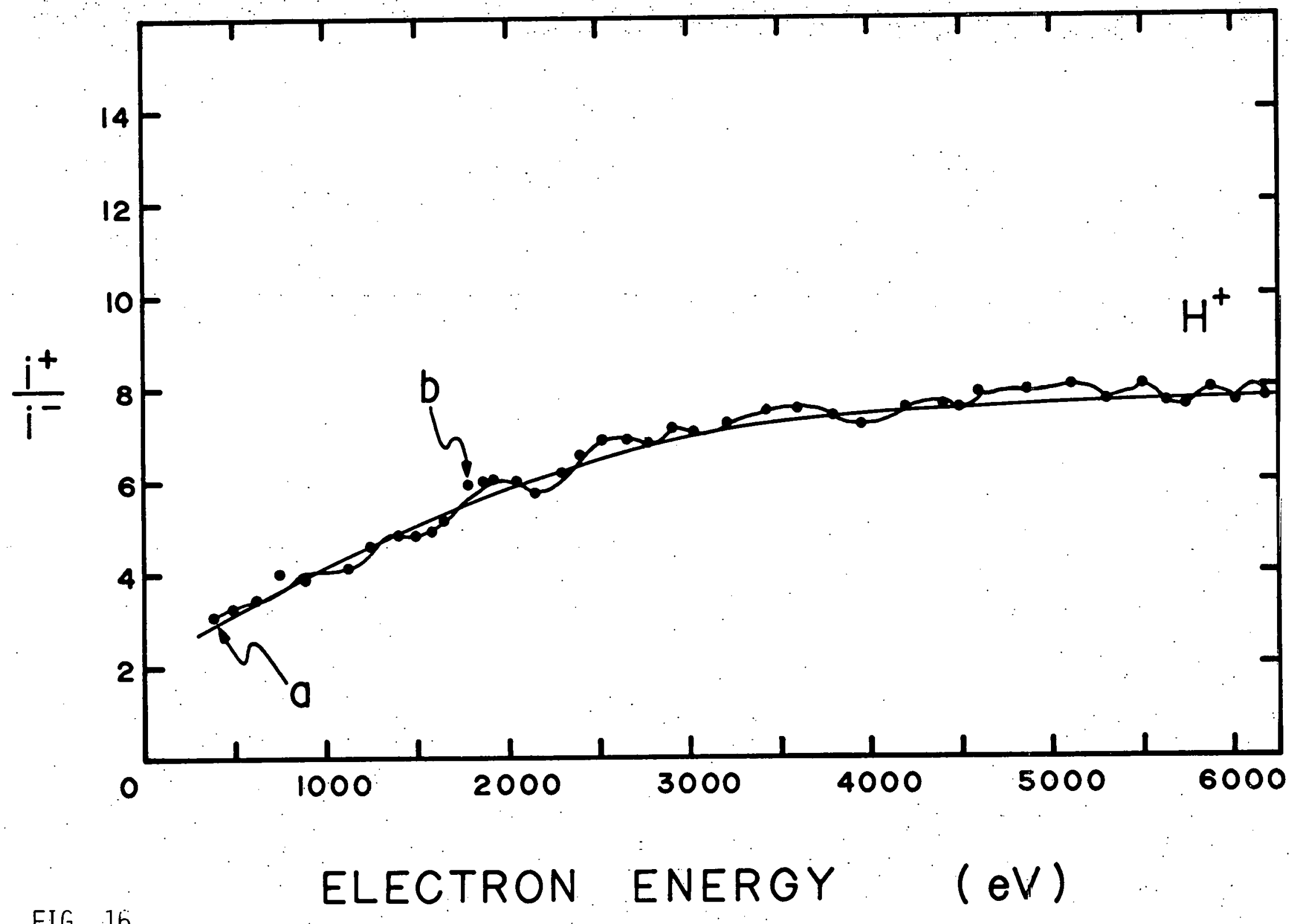

FIG. 16

ELECTRON ENERGY ( $\mathrm{eV})$ 


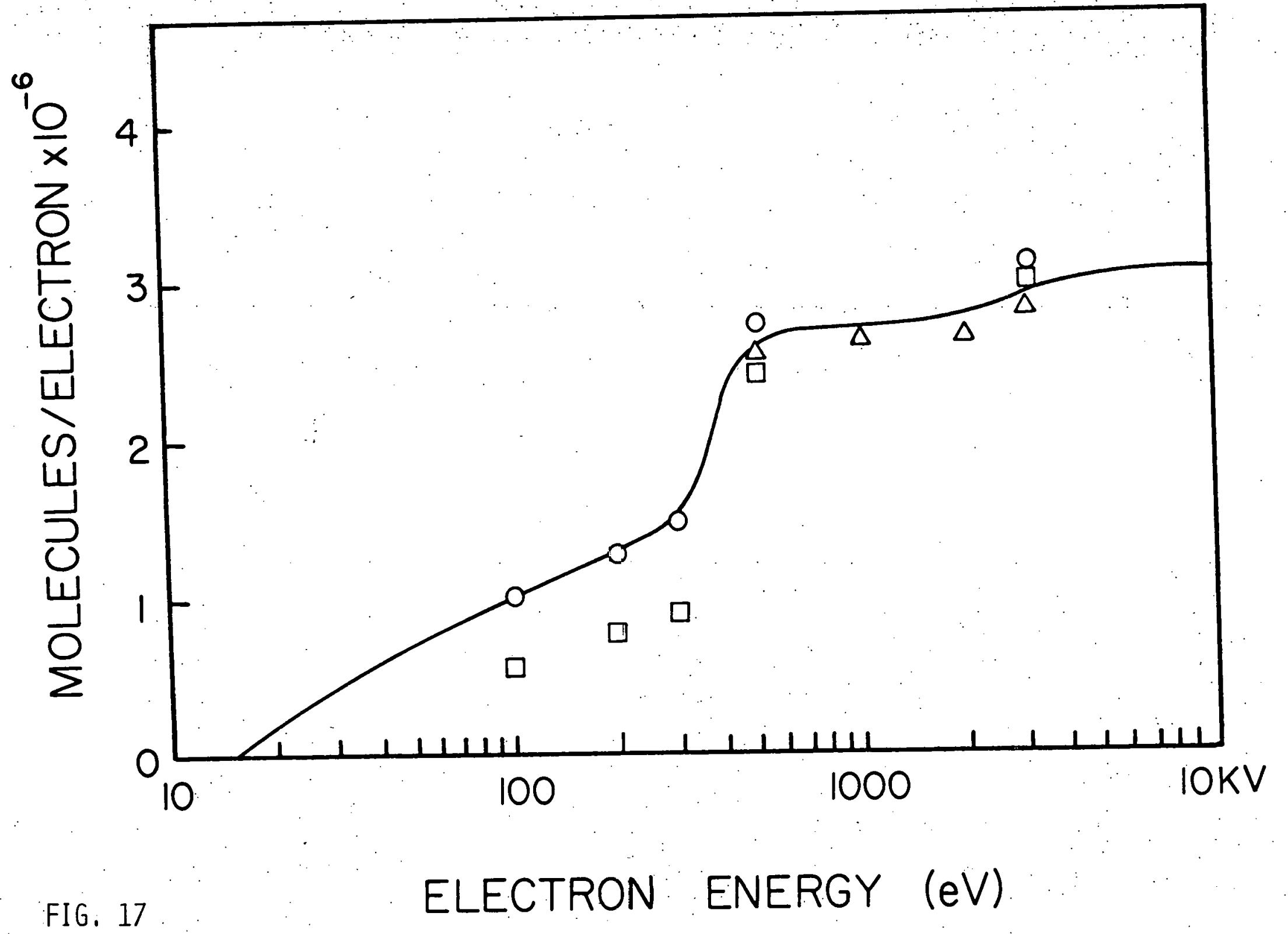




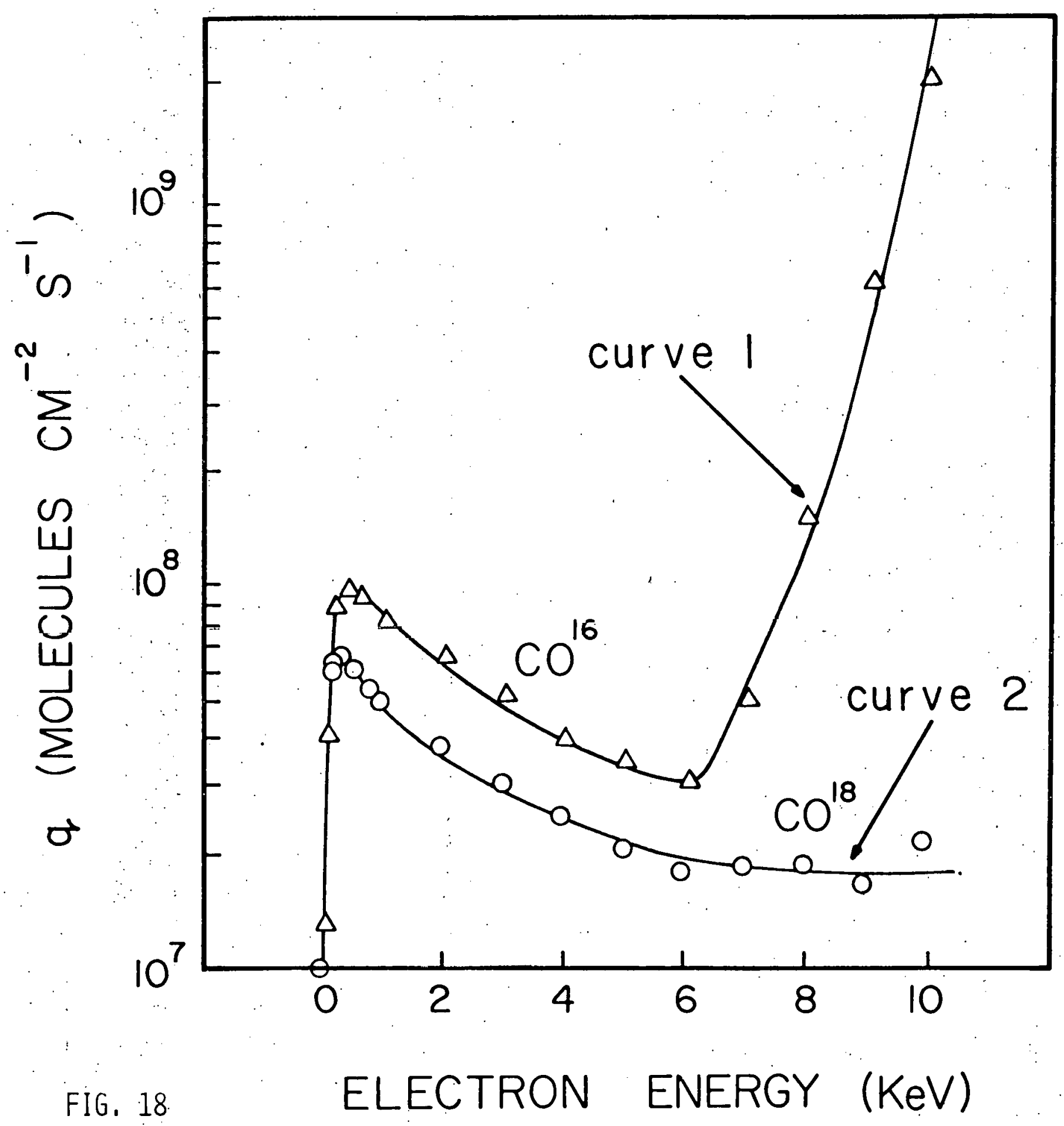

